Finance and Economics Discussion Series Divisions of Research \& Statistics and Monetary Affairs Federal Reserve Board, Washington, D.C.

\title{
A No-Arbitrage Analysis of Economic Determinants of the Credit Spread Term Structure
}

\section{Liuren Wu and Frank Xiaoling Zhang 2005-59}

NOTE: Staff working papers in the Finance and Economics Discussion Series (FEDS) are preliminary materials circulated to stimulate discussion and critical comment. The analysis and conclusions set forth are those of the authors and do not indicate concurrence by other members of the research staff or the Board of Governors. References in publications to the Finance and Economics Discussion Series (other than acknowledgement) should be cleared with the author(s) to protect the tentative character of these papers. 


\title{
A No-Arbitrage Analysis of Economic Determinants of the Credit Spread Term Structure*
}

\author{
LIUREN $\mathrm{WU}^{\dagger}$ \\ Zicklin School of Business, Baruch College \\ FRANK XIAOLING ZHANG \\ Federal Reserve Board
}

First draft: October 20, 2004

This version: May 18, 2005

\footnotetext{
*We thank Linda Allen, Gurdip Bakshi, Turan Bali, Ren-raw Chen, Gregory Duffee, Michael Gordy, Diana Hancock, Paul Harrison, Armen Hovakimian, Don Kim, Patrick McCabe, John Merrick, Til Schuermann, Min Wei, and seminar participants at Baruch College and the Federal Reserve Board for comments. We also thank Brad Howells and Laura Kawano for excellent research assistance. Any remaining errors are ours. The views expressed herein are the authors own and do not necessarily reflect those of the Federal Reserve Board or its staff.

†One Bernard Baruch Way, Box B10-225, New York, NY 10010-5585; Tel: (646) 312-3509; Fax: (646) 312-3451; Email: Liuren_Wu@baruch.cuny.edu; Homepage: http://faculty.baruch.cuny.edu/lwu/.

${ }^{\ddagger}$ Division of Research and Statistics, Federal Reserve Board, Washington, DC 20551; Tel: (202) 452-2581; Fax: (202) 452-5295; Email: Xiaoling. Zhangefrb.gov.
} 


\title{
A No-Arbitrage Analysis of Economic Determinants of the Credit Spread Term Structure
}

\begin{abstract}
This paper presents an internally consistent analysis of the economic determinants of the term structure of credit spreads across different credit rating classes and industry sectors. Our analysis proceeds in two steps. First, we extract three economic factors from 13 time series that capture three major dimensions of the economy: inflation pressure, real output growth, and financial market volatility. In the second step, we build a no-arbitrage model that links the dynamics and market prices of these fundamental sources of economic risks to the term structure of Treasury yields and corporate bond credit spreads. Via model estimation, we infer the market pricing of these economic factors and their impacts on the whole term structure of Treasury yields and credit spreads.

Estimation shows that positive inflation shocks increase both Treasury yields and credit spreads across all maturities and credit rating classes. Positive shocks on the real output growth also increase the Treasury yields, more so at short maturities than at long maturities. The impacts on the credit spreads are positive for high credit rating classes, but become negative and increasingly so at lower credit rating classes. The financial market volatility factor has small positive impacts on the Treasury yield curve, but the impacts are strongly positive on the credit spreads, and increasingly so at longer maturities and lower credit rating classes.

Finally, when we divide each rating class into two industry sectors: financial and corporate, we find that within each rating class, the credit spreads in the financial sector are on average wider and more volatile than the spreads in the corporate sector. Estimation further shows that the term structure of credit spreads in the financial sector is more responsive to shocks in the economic factors.
\end{abstract}

JEL Classification: E43; G12; G13.

Keywords: Credit spreads; term structure; interest rates; macroeconomic factors; financial leverage; volatility; dynamic factor model; Kalman filter. 


\section{A No-Arbitrage Analysis of Economic Determinants of the Credit Spread Term Structure}

Numerous empirical studies, mostly based on regression analysis, show that the frequency of credit events and the expected loss from such events depend crucially on the state of the macroeconomy and the financial market. In this paper, we quantify in an internally consistent manner the link between the dynamics and market prices of the fundamental economic factors on the one hand and the term structure of credit spreads on the other.

The task at hand is important but challenging. First, many macroeconomic numbers and financial market variables are available. Each series contains some information, and also possibly a tremendous amount of noise, about the state of the economy. It is inefficient to focus merely on one or a few of these variables while discarding many others. Meanwhile, it is unrealistic to incorporate all of them as state variables into a formal model of credit spreads. Therefore, how to identify the systematic movements from the many noise series poses the first challenge.

Second, the pricing of credit risk, which is embedded in the prices of many corporate bonds, is likely to be different for bonds at different maturities. Picking bonds at any one maturity or a few maturities would not reveal the complete picture across the whole term structure. Hence, how to consistently summarize and quantify the pricing of different risks across the whole term structure of credit spreads poses another challenge.

In this paper, we handle both challenges by building a dynamic factor model of interest rates and credit spreads. First, we extract a small number of dynamic factors from a wide array of macroeconomic and financial series to capture the key dimensions of the economy. Thus, through a dynamic factor structure, we succinctly summarize the information content in many noisy series. Second, we propose flexible specifications on how these dynamic factors are priced and how the instantaneous interest rates and credit spreads respond to these factors. Given these specifications, we use no-arbitrage arguments as in Duffie and Singleton (1999) and Duffie, Pedersen, and Singleton (2003) to derive the whole term structures of interest rates and credit spreads as functions of these dynamic factors. Therefore, via noarbitrage arguments, we are able to make an internally consistent analysis of the impacts of the large 
number of macroeconomic and financial variables on the interest rates and credit spreads across the whole spectrum of maturities. Furthermore, the estimation not only shows how the variables affect the term structure, but also reveals the reasons behind it. In particular, the model estimation illustrates how different dimensions of risk in the aggregate economy vary over time and how the market prices them differently. Risk dynamics and pricing jointly determine how the factors impact the term structure of interest rates and credit spreads.

Our estimation involves two sequential steps. In the first step, we decompose the economy into three key dimensions: the inflation pressure, the real output growth, and the financial market volatility. Inflation and real output growth represent a first-order decomposition of the two sides of the macroeconomy, whereas financial market volatility represents an aggregate risk measure, a second-order moment that has been generating first-order impacts on the financial market and its operations (Engle (2004)).

We capture these three dimensions of the economy using three systematic dynamic factors, which we extract from 13 observed series using maximum likelihood method joint with Kalman filter. The first two factors are extracted from 11 macroeconomic series, including year-over-year percentage changes on the consumer price index (CPI), the core CPI, the producer price index (PPI), the core PPI, the personal consumption expenditure (PCE) deflator, the core PCE deflator, and the gross domestic production (GDP) deflator, the real GDP, industrial production, non-farm payrolls, and the real PCE. We make structural constraints on the factor loadings to align the first factor with inflation and the second factor with real output growth. We extract the third factor from two volatility indices: the VXO volatility index computed from options on S\&P 100 index, and the VIX volatility index computed from options on S\&P 500 index. This volatility factor represents a compound measure of the economy-wide business risk and financial leverage, both of which impact the credit risk and credit spreads (Merton (1974)).

In the second step, we use the three economic factors to explain the term structure of Treasury yields and corporate bond credit spreads at different credit rating classes. In linking the three dynamic factors to the term structure of Treasury yields and corporate bond credit spreads, we build a noarbitrage dynamic term structure model, under which the whole term structure of Treasury interest rates is determined by the factor dynamics, market prices of factor risks, and the instantaneous riskfree 
interest rate as a function of the factors. A further specification for the instantaneous credit spread function at each credit rating group determines the whole term structure of credit spreads at that rating group. Thus, by estimating the model parameters, we learn the impacts of the systematic factors on the whole term structure of Treasury yields and credit spreads. We also learn the dynamics of the economic factors and how these factors are priced in different markets.

Estimation shows that positive inflation shocks increase Treasury yields and credit spreads across all maturities and credit rating classes. The impacts on the Treasury yields are the strongest. The impacts on the credit spreads are weaker and increasingly so at lower credit ratings. Thus, a positive inflation shock moves up both the benchmark yield curve and the credit spread, more so for the Treasury and credit spreads on high credit rating companies than for spreads on low rating companies.

Positive shocks on the real output growth also increase the Treasury yields, more so at short maturities than at long maturities. The impacts on the credit spreads are positive for high credit rating classes, but become negative and increasingly so as the credit rating moves to a lower class. Furthermore, the impacts are more negative at shorter maturities than at longer maturities. Thus, a positive shock to the real side of the economy increases the benchmark interest-rate level, flattens an otherwise upward sloping yield curve, but narrows the credit spread, particularly at short maturities and low credit rating classes.

The volatility factor has only small positive impacts on the Treasury yield curve, but its impacts are strongly positive on the credit spreads, and increasingly so at longer maturities and lower credit rating classes.

We also divide each credit rating group into two broad industry sectors: financial and corporate, and study whether the impacts differ significantly across these two industry sectors. We find that credit spreads on the financial sector are on average wider and more volatile than the spreads on corporate sector, especially at lower credit rating classes. Estimation further shows that the term structure of credit spreads in the financial sector is more responsive to shocks in the economic factors. In particular, we find that for the financial sector, the impacts of the inflation factor are more positive across all rating classes, that the impacts of the real output factor are more negative for the BBB class, and the impacts of the volatility factor more positive for AA, A, and BBB classes. 
Our work in this paper integrates two strands of extant literature. The first strand uses regressions to analyze the determinants of credit spreads. Prominent examples include Bevan and Garzarelli (2000), Frye (2000), Carey (1998), Pedrosa and Roll (1998), Collin-Dufresne, Goldstein, and Martin (2001), Elton, Gruber, Agrawal, and Mann (2001), and Altman, Brady, Resti, and Sironi (2004). Though rich in economic intuition, the results of these studies often depend on the specific choices of the explanatory variables, as well as the choices of the maturity and credit rating of the credit spreads used as the dependent variable. Given the correlations among the many commonly used explanatory variables, the regression coefficient estimates often change depending on the choice of the other explanatory variables. Furthermore, the estimates also change when the credit spreads used in the analysis switch maturities or credit rating classes. It asks for a dramatic leap of faith to extend the regression results from one maturity and/or rating class to other maturities and rating classes.

The second strand of literature uses a small number of dynamic factors to summarize the variation on the term structure of interest rates and credit spreads via no-arbitrage arguments. Important contributions include Jones, Mason, and Rosenfeld (1984), Longstaff and Schwartz (1995), Duffie and Singleton (1997), Duffee (1999), Nickell, Perraudin, and Varotto (2000), Liu, Longstaff, and Mandell (2000), Delianedis and Geske (2001), Bangia, Diebold, Kronimus, Schagen, and Schuermann (2002), Collin-Dufresne, Goldstein, and Helwege (2003), Huang and Huang (2003), Bakshi, Madan, and Zhang (2004), Longstaff, Mithal, and Neis (2004), Eom, Helwege, and Huang (2003), and Longstaff, Mithal, and Neis (2004). Different from the regression analysis, these studies can derive the impacts of the dynamic factors on the whole term structure of interest rates and credit spreads in an internally consistent manner. However, most of these studies rely on latent factors, directly derived from the yield curve and credit spread term structure. The economic meanings of these latent factors are not clear. In the few studies that try to incorporate economic variables, often only a small number of observable variables are included for tractability reasons, and other valuable economic variables are conspicuously left out. In this paper, we exploit the advantages of both strands of studies. On the one hand, we use a few dynamic factors to summarize the information and suppress the noises in many observed macroeconomic and financial time series. On the other hand, we exploit the no-arbitrage framework to provide an internally consistent analysis on the impacts of these macroeconomic and financial series across the 
whole term structure of credit spreads. We also rely on the no-arbitrage model to provide insights on risk dynamics and risk pricing that form the main driving force behind the term structure impacts.

The rest of the paper is organized as follows. Section I describes the procedure for extracting the dynamic economic factors. Section II presents a no-arbitrage model that links the dynamic economic factors to the whole term structure of Treasury and corporate bond yields. Section III describes the construction of Treasury and corporate yields and our estimation strategy. Section IV discusses the estimation results of the no-arbitrage models, and examines the relation between credit spreads across different maturities and rating classes and the extracted economic factors. Section V further divides the corporate bond data at each rating class into two broad industry sectors and analyze how the term structure of credit spreads differ and whether the economic factors impact the term structure differently across the two sectors. Section VI concludes.

\section{Extracting Dynamic Economic Factors}

We observe many economic and financial time series, yet many of them contain similar information, mingled with a significant portion of noises either due to measurement errors or idiosyncratic movements. We use a dynamic factor model to succinctly summarize the information and suppress the noise in many observed macroeconomic and financial series.

\section{A. Important Dimensions of the Aggregate Economy}

In applying a dynamic factor model, we first need to specify the dimensions of the factor space. Based on both empirical evidence and economic rationale, we decompose the aggregate economy into three broad dimensions: (1) the nominal side of the economy, (2) the real side of the economy, and (3) the volatility of the financial market.

Macroeconomists often decompose the economy into the nominal and real sides and argue that shocks to the two sides of the economy should be separated and treated differently. For example, Woodford (2003) argues from the perspective of monetary policy that nominal shocks should be minimized whereas real shocks should not be intervened. Early studies by Sargent and Sims (1977), Sargent 
(1989), and Stock and Watson (1989) also suggest that a nominal and a real factor can account for much of the observed variation in major economic aggregates.

In addition to these two dimensions, we also incorporate a financial market volatility dimension, which captures the compound effect of economy-wide business risk and financial leverage, both of which impact the credit risk according to the classic structural model of Merton (1974). Furthermore, the 2004 Nobel price in economics manifests the first-order importance of modeling the time-varying dynamics of this second-order moment (Engle (2004)).

Thus, we use three systematic factors to capture the dynamic variation in the first and second moments of the aggregate economy. Regression analysis in the literature often incorporates many more explanatory variables, but in the aggregate level most of these variables can be classified into one of the three dimensions. At a firm level, financial leverage directly impacts credit risk and credit spreads, but it is more a capital structure decision (control) variable than a separate dimension of exogenous shocks.

\section{B. Estimating Dynamic Factor Models with Maximum Likelihood and Kalman Filter}

We describe the economy by fixing a filtered probability space $\left\{\Omega, \mathcal{F}, \mathbb{P},\left(\mathcal{F}_{t}\right)_{0 \leq t \leq \mathcal{T}}\right\}$, with some fixed long horizon $\mathcal{T}$. We use $X \in \mathbb{R}^{n}$ to denote an $n$-dimensional vector Markov process that represents the systematic state of the economy. As discussed above, we set $n=3$. We further assume that the state vector $X$ follows simple VAR(1) dynamics. Under continuous-time notation, $X$ follows a multi-variate Ornstein-Uhlenbeck process under the statistical measure $\mathbb{P}$,

$$
d X_{t}=-\kappa X_{t} d t+d W_{t}
$$

where $W_{t}$ denotes an $n$-dimensional standard Brownian motion and $\kappa$ controls the mean-reversion speed of the states. For identification purpose, we normalize the long-run mean of the states $X$ to zero and the instantaneous covariance matrix to be an identity matrix. We also constrain $\kappa$ to be a lower triangular matrix.

Next, let $y \in \mathbb{R}^{N}$ denote a set of macroeconomic and financial time series. The dimension $N$ can be very large, and much larger than the dimension of the state of the economy, $N \gg n$. In this paper, 
we choose $N=13$, which includes seven inflation-related series, four output-related series, and two financial market volatility indices constructed from stock index options. We summarize the systematic movements underlying the 13 macroeconomic and financial series using three dynamic economic factors via the following linear factor structure,

$$
y_{t}=H X_{t}+e_{t},
$$

where $H$ is an $(N \times n)$ matrix of factor loading coefficients and $e_{t}$ denotes an $(N \times 1)$ vector of measurement errors of the data series. We use $\mathcal{R}^{y}=\mathbb{E}\left[e_{t} e_{t}^{\top}\right]$ to denote the covariance matrix of the measurement errors. We assume that the measurement errors are independent of the state vector. In our estimation, we further assume that the measurement errors are mutually independent, but with distinct variance: $\mathcal{R}_{i i}^{y}=\sigma_{i}^{2}, i=1, \cdots, N$, and $\mathcal{R}_{i j}^{y}=0$ for $i \neq j$.

If we know the parameters that govern the factor dynamics ( $\kappa)$, the factor loadings $(H)$, and the measurement error variance $\left(\mathcal{R}^{y}\right)$, we can infer the systematic states of the economy from the observed data series, with the technique of Kalman filtering. For this purpose, we rewrite the economic factor dynamics in its discrete-time analog,

$$
X_{t}=\Phi X_{t-1}+\sqrt{Q} \varepsilon_{t}
$$

where $\Phi=\exp (-\kappa \Delta t), Q=I \Delta t, \varepsilon_{t}$ denotes an $(n \times 1)$ iid standard normal random vector, $\Delta t$ denotes the discrete time interval, and $I$ denotes an identity matrix of the relevant dimension. With monthly time interval, we set $\Delta t=1 / 12$.

For Kalman filtering, we regard equation (3) as our state-propagation equation and equation (2) as our measurement equation. Let $\bar{X}_{t}, \bar{V}_{t}, \bar{y}_{t}, \bar{A}_{t}$ denote the time- $(t-1)$ ex ante forecasts of time- $t$ values of the systematic economic factors, the covariance matrix of the economic factors, the measurement series, and the covariance matrix of the measurement series. Let $\widehat{X}_{t}$ and $\widehat{V}_{t}$ denote the ex post update, or filtering, on the economic factors and their covariance at time $t$ based on observations $\left(y_{t}\right)$ at time $t$. 
The Kalman filter provides the efficient updates on these quantities. Specifically, we have the ex ante predictions as

$$
\begin{aligned}
\bar{X}_{t} & =\Phi \widehat{X}_{t-1} ; \\
\bar{V}_{t} & =\Phi \widehat{V}_{t-1} \Phi^{\top}+Q ; \\
\bar{y}_{t} & =H \bar{X}_{t} ; \\
\bar{A}_{t} & =H \bar{V}_{t} H^{\top}+\mathcal{R}^{y} .
\end{aligned}
$$

The ex post filtering updates are,

$$
\begin{aligned}
\widehat{X}_{t+1} & =\bar{X}_{t+1}+K_{t+1}\left(y_{t+1}-\bar{y}_{t+1}\right) ; \\
\widehat{V}_{t+1} & =\bar{V}_{t+1}-K_{t+1} \bar{A}_{t+1} K_{t+1}^{\top},
\end{aligned}
$$

where $K_{t+1}=\bar{V}_{t+1} H^{\top}\left(\bar{A}_{t+1}\right)^{-1}$ is the Kalman gain.

Thus, we can obtain a time series of the ex ante forecasts and ex post updates on both the mean and covariance of the economic factors and the data series, via the iterative procedure defined by equations (4) to (9). To estimate model parameters $\Theta \equiv\left[\kappa, H, \mathcal{R}^{y}\right]$ that govern the factor dynamics and factor loading, we define the monthly log likelihood function by assuming that the forecasting errors on the observed time series are normally distributed,

$$
l_{t+1}(\Theta)=-\frac{1}{2} \log \left|\bar{A}_{t+1}\right|-\frac{1}{2}\left(\left(y_{t+1}-\bar{y}_{t+1}\right)^{\top}\left(\bar{A}_{t+1}\right)^{-1}\left(y_{t+1}-\bar{y}_{t+1}\right)\right) .
$$

The parameters are estimated by maximizing the sum of the monthly log likelihood values,

$$
\Theta=\arg \max _{\Theta} \sum_{t=1}^{T-1} l_{t+1}(\Theta),
$$

where $T$ denotes the number of observations for each series. 


\section{Data Description}

Our estimation is based on 13 monthly or quarterly macroeconomic and financial series from January 1988 to June 2004. The 11 macroeconomic series are from the Federal Reserve Board. They include seven inflation-related series: the consumer price index (CPI), the core $\mathrm{CPI}$, the producer price index (PPI), the core PPI, the personal consumption expenditure (PCE) deflator, the core PCE deflator, and the gross domestic production (GDP) deflator. The GDP deflator is available at quarterly frequency. All other variables are available in monthly frequency. We first convert the price indexes into year-overyear percentage changes, and then standardize each series by subtracting the sample mean and dividing the series by the sample standard deviation.

The CPI measures the average change in the prices of a basket of goods and services bought by a typical urban household. The PPI measures the change in the selling prices received by domestic producers for all finished goods. The PCE deflator measures the average change in the prices of a basket of goods and services purchased by the typical consumer such as individuals and non-profit organizations. Their respective core measures exclude food and energy, the prices of which tend to be highly volatile. The GDP deflator measures the average change in prices of all goods and services produced by the domestic economy.

Among the seven inflation measures, the CPI is the most cited inflation measure, but the price changes at the wholesale level, as captured by the PPI numbers, are often passed through to the consumer price index in a later date. Hence, tracking price pressures from the PPI numbers, investors can anticipate inflationary consequences in the coming months. On the other hand, the PCE deflator is becoming the most watched price index from the standpoint of monetary policy and is considered as a "more reliable measure of inflation" by the Federal Reserve ${ }^{1}$ for two major reasons. First, whereas the CPI is only representative of the price paid by urban customers, the PCE deflator is a broader measure that covers both urban and rural customers. Second, the PCE deflator is a chain-weighted index that captures shifting spending patterns. In contrast, the CPI is a fixed-weight index that relies on spending patterns several years ago. Each of the above three indices has a corresponding core measure that ex-

\footnotetext{
${ }^{1}$ Quotes are from the testimony of Alan Greenspan before the Committee on Financial Services, U.S. House of Representatives, July 18, 2001.
} 
cludes food and energy. Many economists and investors prefer the core measures because they think that shocks to energy prices are often transitory. Others disagree. Finally, since the GDP deflator includes all goods and services produced by the domestic economy, it is the most comprehensive measure of inflation. However, the GDP deflator is released quarterly while all other inflation measures are released monthly. In our application, we do not take a stance on which of the seven series provides the most accurate and timely measure of the inflationary pressure. Instead, we include all of them into our estimation and extract one common factor that captures the systematic movements in inflation pressure.

The data set also includes four output and employment series: the real GDP, industrial production, non-farm payrolls, and the real PCE. The real GDP is available in quarterly frequency. The other three series are available in monthly frequency, but the data on real PCE start at a later date in January 1991. The real GDP growth is the broadest measure of the output growth of the domestic economy. Industrial production measures the production of goods. Although it is less comprehensive, it is more timely since the industrial production numbers are released monthly whereas the GDP numbers are released quarterly. Non-farm payrolls measure the number of employees on firms' payrolls. Farms are excluded because of their seasonal nature, which can skew total employment figures. This number is a key indicator of the employment scenario of the economy, which has far-reaching implications for both inflation and output growth. On the demand side of the economy, we include real personal consumption expenditure, which often indicates changes in the state of the economy prior to changes in production. Again, we first turn the four series into year-over-year growth rates and then standardize them before we extract the real growth factor.

To extract a financial market volatility factor, we include two volatility indexes: the VXO index computed from options on S\&P 100 index, and the VIX volatility index computed from options on S\&P 500 index. The VXO measures the one-month at-the-money Black and Scholes (1973) implied volatility on the S\&P 100 index options, and the VIX is a specific portfolio of option prices that approximate the one-month variance swap rate on the S\&P 500 index returns (Carr and $\mathrm{Wu}$ (2004)). Both series are available from Bloomberg in daily frequency, but the VIX series starts at a later date in January 1990. The two series exhibit a large amount of short-term variations. To reduce noise, we compute the yearly moving average of the daily volatility series. Then, we sample the moving averages at the 
end of each month and extract the volatility factor in monthly frequency. Given the documented level dependence on the volatility of volatility, we first take logs on two series and then standardize them before we extract the volatility factor. Given the positivity of volatilities, talking logs also match our Gaussian factor specification better.

In principle, factors can rotate and the loadings can change accordingly without impacting the final result. However, such rotations make it difficult to interpret the economic meanings of the dynamic factors. To improve identification and enhance the economic interpretation of the factors, we put structural constraints on the factor loading matrix. Specifically, we constrain the first factor to have positive loadings on the seven inflation series and the non-farm payroll series and zero loadings on all other series. As such, this first dynamic factor summarizes the inflation pressure in the economy. We constrain the second factor to have nonzero loadings only on real GDP, industrial production, non-farm payroll, and the real component of the personal consumption expenditure. Thus, it summarizes the real part of the macroeconomy, which we label as a real output factor. Finally, we constrain the third factor to have nonzero loadings only on the two financial market volatility indexes to make it a financial market volatility factor.

We estimate the dynamic factors in monthly frequency. For data series that are only available in quarterly frequency or at a later date, we fill the series with missing values. Our estimation method readily accommodates missing data. At each month, we update the dynamic factors based on the available subset of the data.

\section{The Time-Series Dynamics of the Economic Factors}

Table I reports the estimates of the factor loading matrix $(H)$ and the measurement error variance $\left(R^{y}\right)$, with the absolute magnitude of the $t$-statistics for the parameter estimates reported in parentheses. The last column reports the predicted variation (PV), defined as one minus the ratio of the forecasting error variance over the variance of the original series. Since each series is standardized to have unit unconditional variance, the measurement error variance reflects the relative goodness of fit for each macroeconomic series. The smaller the measurement error variance is, the higher percentage variation the three dynamic factors can explain. Similarly, PV measures the predictive performance of the three 
dynamic factors on each of the 13 series. It also reflects the relative informativeness of 13 series in terms of their affinity to the extracted economic factors.

Among the seven inflation variables, the smallest measurement error variance and highest predicted variation both come from the PCE deflator, consistent with the Federal Reserve's emphasis on this measure as a more reliable gauge of the inflation pressure. On the other hand, the largest error variance and lowest predicted variation both come from PPI, showing that this series is the most noisy or least informative about the inflation pressure. Nevertheless, the loading estimates on all seven series are statistically significant and positive, suggesting that all seven measures contain useful information about the state of inflation. Hence, it is appropriate to use them all instead of picking one against the other.

The non-farm payrolls number is a key indicator of the employment scenario of the economy, it has far-reaching implications for both inflation and output growth. Hence, we also allow the first factor to have a nonzero loading on the non-farm payrolls series. The loading estimates are smaller than those on the seven inflation variables, but the high $t$-statistics suggest that this loading estimate is strongly significant and that non-farm payrolls are indeed informative about the inflation pressure of the economy.

Among the four output and employment series, non-farm payrolls also have the highest loading and highest $t$-statistics on the second factor. Furthermore, the measurement error variance estimate on non-farm payrolls is neither visually nor statistically different from zero and the predicted variation is highest among all 11 macroeconomic series, showing that the non-farm payrolls series is the most informative about the economy. Again, however, all four series have significantly positive loadings on the second factor. Hence, they are all informative about the real side of the economy.

Finally, for the two volatility index series VXO and VIX, the measurement error variance estimates are both small and the predicted variations are high. The loading estimates on the two series are also similar, suggesting that the two indices move closely together.

Table II reports the parameter estimates for $\kappa$, which control the dynamics of the three macroeconomic and financial factors. For identification, we assume a lower triangular structure for the $\kappa$ matrix. Thus, the ranking of the three factors determines their dependence structure. We let inflation be the 
first factor. Thus, the prediction of this factor only depends on its own past value. The estimate of 0.1139 corresponds to a monthly autocorrelation of 0.9906 , showing the high persistence of inflation. The second factor is real output, the conditional mean of which depends on lagged values of both the inflation factor and the output factor itself. The estimate of 0.2007 corresponds to a monthly autocorrelation of 0.9834 , lower than that for the inflation factors. The off-diagonal term 0.4891 indicates that past values of the inflation factor predict negatively on the changes in the real output. Thus, the two macroeconomic factors show negative cross-correlation. The third factor is the volatility factor, which responds negatively to inflation, but positively to output. The small diagonal value suggests that the volatility factor is highly persistent, in part reflecting the effect of our moving average smoothing.

Given the parameter estimates, the Kalman filter generates the ex post updated values of the three dynamic factors from the 13 observed series. Figure 1 plots the time series dynamics of the three extracted economic factors. The solid line depicts the inflation factor, the dashed line depicts the real output growth factor, and the dash-dotted line depicts the financial market volatility factor. The inflation factor had a hike in early 1991, coinciding with the spike in inflation pressure caused by energy shocks during the first Gulf War. The inflationary pressure quickly receded and stayed low for the rest of the sample period.

[Figure 1 about here.]

The dashed line for the real output growth shows two periods of sharp slowdown and one period of prolonged high output growth. The first slowdown coincided with the 1991-1992 recession. From mid 1994 to late 2000, the output growth factor remained at high values with some fluctuation. The factor started another very steep fall in early 2001, reflecting the sharp slowdown of the output growth, and reached the bottom in the second quarter of 2002. The output growth has picked up since then. This upswing is still continuing as of now, and the current level of this factor is still way below its level reached in 2000.

The volatility factor extracted from stock index options, as shown by the dash-dotted line, started high in late 1980s, showing the lingering effects of the 1987 stock market crash. The first Gulf War caused a spike on the stock market volatility, but otherwise the volatility stayed low between 1992 and 
1997. The stock market volatility increased in late 1997 following the Asian crises and then the Russian default and the ensuing hedge fund crisis. Stock market volatility peaked around late 2002 and early 2003 after a series of corporate scandals including Enron and WorldCom defaults and the war in Iraq. Since the spring of 2003, the stock market volatility started to come down.

\section{A No-Arbitrage Dynamic Term Structure Model of Interest Rates and Credit Spreads with Observable Economic Factors}

We propose a dynamic term structure model that applies no-arbitrage arguments to link the dynamic economic factors extracted in the previous section to the whole term structure of default-free interest rates on Treasury bonds and credit spreads on corporate bonds at different credit rating classes and industry sectors.

\section{A. Market Prices of Factor Risks and Risk-Neutral Factor Dynamics}

The previous section has specified the factor dynamics in equation (1), or its discrete version in equation (3). To price Treasury and corporate bonds based on the extracted dynamic factors, we need to specify how the market prices risks that are inherent in the dynamic factors. We consider a flexible affine specification for the market price of risks in the dynamic factors,

$$
\gamma\left(X_{t}\right)=\gamma_{0}+\gamma_{1} X_{t}
$$

where $\gamma_{0}$ is an $(n \times 1)$ vector and $\gamma_{1}$ is an $(n \times n)$ matrix, which we constrain to be lower triangular. Thus, the market price has both a constant component and a component that varies with the factor level. Via model estimation, we determine the magnitude of the market prices and whether and how they vary with the state of the economy.

The market price specification in (12) and no-arbitrage arguments dictate that there exists a riskneutral measure $\mathbb{Q}$ that is absolutely continuous with respect to the statistical measure $\mathbb{P}$, such that the fair value of a financial asset, $V_{t}$, is equal to the expected value, with the expectation taken under this 
new measure $\mathbb{Q}$, of its future payoff streams, $\pi_{s}, s>t$, discounted by the corresponding instantaneous risk-free interest rate $r_{s}$ :

$$
V_{t}=\mathbb{E}^{\mathbb{Q}}\left[\int_{t}^{\infty} \exp \left(-\int_{t}^{s} r_{u} d u\right) \pi_{s} d s \mid \mathcal{F}_{t}\right]
$$

where $\mathbb{E}^{\mathbb{Q}}\left[\cdot \mid \mathcal{F}_{t}\right]$ denotes the expectation operator under measure $\mathbb{Q}$ conditional on the filtration $\mathcal{F}_{t}$. The measure change from the statistical measure $\mathbb{P}$ to the risk-neutral measure $\mathbb{Q}$ is defined by the following exponential martingale,

$$
\left.\frac{d \mathbb{Q}}{d \mathbb{P}}\right|_{t} \equiv \mathcal{E}\left(-\int_{0}^{t} \gamma\left(X_{s}\right)^{\top} d W_{s}\right)=\mathcal{E}\left(-\int_{0}^{t}\left(\gamma_{0}+\gamma_{1} X_{s}\right)^{\top} d W_{s}\right)
$$

where $\mathcal{E}(\cdot)$ denotes the Doléans-Dade exponential operator. According to the Girsanov theorem, the factor dynamics remain Ornstein-Uhlenbeck under the risk-neutral measure $\mathbb{Q}$,

$$
d X_{t}=\kappa^{\mathbb{Q}}\left(\theta^{\mathbb{Q}}-X_{t}\right) d t+d W_{t}^{\mathbb{Q}}
$$

with $\kappa^{\mathbb{Q}} \boldsymbol{\theta}^{\mathbb{Q}}=-\gamma_{0}$ being an $(n \times 1)$ vector and $\kappa^{\mathbb{Q}}=\kappa+\gamma_{1}$ being an $(n \times n)$ lower triangular matrix.

\section{B. The Term Structure of Treasury Yields}

To model the term structure of Treasury yields, we assume that the instantaneous default-free interest rate is affine in the three dynamic factors,

$$
r_{t}=r\left(X_{t}\right)+\varepsilon_{t}^{r}, \quad r\left(X_{t}\right)=a_{r}+b_{r}^{\top} X_{t},
$$

where $\varepsilon_{t}^{r}$ denotes the instantaneous interest rate moves that are not explained by the three dynamic factors. By design, $X_{t}$ or $r\left(X_{t}\right)$ is orthogonal to $\varepsilon_{t}^{r}$.

According to the fundamental valuation equation in (13), the time- $t$ fair value of a default-free zero-coupon bond with time-to-maturity $\tau$ is

$$
\begin{aligned}
B(t, \tau) & =\mathbb{E}^{\mathbb{Q}}\left[\exp \left(-\int_{t}^{t+\tau} r\left(X_{s}\right) d s\right) \mid \mathcal{F}_{t}\right] \mathbb{E}^{\mathbb{Q}}\left[\exp \left(-\int_{t}^{t+\tau} \varepsilon_{s}^{r} d s\right) \mid \mathcal{F}_{t}\right] \\
& =B\left(X_{t}, \tau\right) E(t, \tau)
\end{aligned}
$$


where the multiplicative decomposition follows from the orthogonality assumption between $X$ and $\varepsilon^{r}$. We leave the dynamics of $\varepsilon_{t}^{r}$ unspecified and regard $E(t, \tau)$ as an error term on the zero-coupon bond price that is not explained by the three dynamic economic factors.

The specification of the $\mathbb{Q}$-dynamics for the factors $X_{t}$ in (15) and the instantaneous default-free interest-rate function $r\left(X_{t}\right)$ in (16) satisfy the affine condition of Duffie and Kan (1996) and Duffie, Pan, and Singleton (2000). Thus, we can solve $B\left(X_{t}, \tau\right)$ as an exponential-affine function of the economic factors,

$$
B\left(X_{t}, \tau\right)=\exp \left(-a(\tau)-b(\tau)^{\top} X_{t}\right)
$$

where the coefficients $[a(\tau), b(\tau)]$ are solutions to the following ordinary differential equations:

$$
\begin{aligned}
& a^{\prime}(\tau)=a_{r}-b(\tau)^{\top} \gamma_{0}-b(\tau)^{\top} b(\tau) / 2, \\
& b^{\prime}(\tau)=b_{r}-\left(\kappa^{\mathbb{Q}}\right)^{\top} b(\tau),
\end{aligned}
$$

subject to the boundary conditions $a(0)=0$ and $b(0)=0$. The ordinary differential equations can be readily solved using standard numerical procedures.

Given the exponential-affine solution in (18), the continuously compounded spot rates are affine functions of the three economic factors,

$$
R\left(X_{t}, \tau\right) \equiv-\frac{\ln B\left(X_{t}, \tau\right)}{\tau}=\left[\frac{a(\tau)}{\tau}\right]+\left[\frac{b(\tau)}{\tau}\right]^{\top} X_{t}
$$

The observed spot rate, $R(t, \tau)$, can be written as

$$
R(t, \tau)=R\left(X_{t}, \tau\right)+e(t, \tau)
$$

where $e(t, \tau) \equiv-\ln E(t, \tau) / \tau$ denotes the portion of the spot rate that is not explained by the three economic factors. In our estimation, we treat $e(t, \tau)$ as the measurement error term. 


\section{The Term Structure of Corporate Yields and Credit Spreads}

For defaultable bonds, Duffie and Singleton (1999) and Duffie, Pedersen, and Singleton (2003) show that the valuation can be written in analogous forms by adjusting the risk-free discounting with an instantaneous credit spread. Specifically, the time- $t$ value of a zero-coupon defaultable bond with time-to-maturity $\tau, D(t, \tau)$, can be written as,

$$
D(t, \tau)=\mathbb{E}^{\mathbb{Q}}\left[\exp \left(-\int_{t}^{t+\tau}\left(r_{u}+s_{u}\right) d u\right) \mid \mathcal{F}_{t}\right]
$$

where $s_{t}$ denotes the instantaneous default spread, which can be thought of as a reduced-form product of default probabilities and loss given default. In addition, it can also be used to capture spreads induced by liquidity and other factors.

To price corporate bonds at a certain credit rating class (and/or industry sector) $i$, we assume that the instantaneous credit spread for that rating class, $s_{t}^{i}$, is an affine function of the three economic factors,

$$
s_{t}^{i}=s^{i}\left(X_{t}\right)+\varepsilon_{t}^{i}, \quad s^{i}\left(X_{t}\right)=a_{i}+b_{i}^{\top} X_{t},
$$

where $\varepsilon_{t}^{i}$ denotes the portion of the spread that is not explained by the three economic factors.

Then, we can show analogously that the fair value of the zero-coupon bond in the $i$ th credit rating group is also exponential affine in the three dynamic economic factors,

$$
D_{i}(t, \tau)=D_{i}\left(X_{t}, \tau\right) E_{i r}(t, \tau), \quad \text { with } \quad D_{i}\left(X_{t}, \tau\right)=\exp \left(-a_{i}(\tau)-b_{i}(\tau)^{\top} X_{t}\right)
$$

where $E_{i r}(t, \tau)$ is the error term induced by the unexplained movements in both the default-free rate and the credit spread: $\varepsilon^{r}+\varepsilon^{i}$, and the coefficients $\left[a_{i}(\tau), b_{i}(\tau)\right]$ are solutions to the following ordinary differential equations:

$$
\begin{aligned}
& a_{i}^{\prime}(\tau)=\left(a_{r}+a_{i}\right)-b_{i}(\tau)^{\top} \gamma_{0}-b_{i}(\tau)^{\top} b_{i}(\tau) / 2, \\
& b_{i}^{\prime}(\tau)=\left(b_{r}+b_{i}\right)-\left(\kappa^{\mathbb{Q}}\right)^{\top} b_{i}(\tau),
\end{aligned}
$$


subject to the boundary conditions $a_{i}(0)=0$ and $b_{i}(0)=0$.

The continuously compounded spot rate on the defaultable bond is affine in the economic factors,

$$
R_{i}\left(X_{t}, \tau\right) \equiv-\frac{\ln D_{i}\left(X_{t}, \tau\right)}{\tau}=\left[\frac{a_{i}(\tau)}{\tau}\right]+\left[\frac{b_{i}(\tau)}{\tau}\right]^{\top} X_{t}
$$

The observed spot rate on the defaultable bond can be written as

$$
R_{i}(t, \tau) \equiv-\frac{\ln D_{i}(t, \tau)}{\tau}=R_{i}\left(X_{t}, \tau\right)+e_{i r}(t, \tau)
$$

with $e_{i r}(t, \tau) \equiv-\ln E_{i r}(t, \tau) / \tau$.

We define the credit spread on the corporate bond as the difference between the spot rate on the defaultable bond and the corresponding spot rate on the Treasury:

$$
S_{i}(t, \tau) \equiv R_{i}(t, \tau)-R(t, \tau)=\left[\frac{a_{i}(\tau)-a(\tau)}{\tau}\right]+\left[\frac{b_{i}(\tau)-b(\tau)}{\tau}\right]^{\top} X_{t}+e_{i}(t, \tau)
$$

with $e_{i}(t, \tau)=e_{i r}(t, \tau)-e(t, \tau)$. Thus, via no-arbitrage arguments, we link the credit spreads across all maturities at a certain credit rating class to the observable dynamic economic factors. The no-arbitrage links are determined by the factor dynamics, the market prices of factor risks, and by the instantaneous default-free interest rate and credit spread as functions of these factors. The model provides the theoretical basis and economic insights on the determinants of the Treasury yields and corporate bond credit spreads.

\section{Data and Estimation}

\section{A. Constructing the Treasury Yields}

The Treasury yields data are monthly continuously compounded spot rates obtained from the Federal Reserve Board, which extracts the rates from the Treasury notes and bond prices following the procedure proposed by Svensson (1995). The spot rates are available at 12 maturities: three months, 
six months, and every year from one to ten years. We use the same sample period as for the economic factors from January 1988 to October 2004.

Table III reports the summary statistics of the Treasury yields. Over the 15 years of sample period, the mean Treasury yield show an upward sloping term structure. The standard deviation are larger for short-term yields than for long-term yields. Both skewness and kurtosis estimates for the Treasury

yields are small. The Treasury yields show strong persistence, with monthly autocorrelation ranging from 0.973 to 0.986 .

The left panel of Figure 2 plots the time series of Treasury yields over the 15-year sample period. The plot shows two periods of low interest rates with steep yield curves at around 1993 and 2003, respectively, each incidence following the trough of the real output factor in Figure 1. The Treasury interest rates are high and the term structure flat in the late 1980s and also in the extended high-growth period of the later 1990s.

[Figure 2 about here.]

The right panel in Figure 2 plots the term structure of the Treasury spot rates at each month of our sample period. The bold solid line denotes the mean upward-sloping term structure. Our sample period has witnessed a variety of term structure patterns, including upward sloping, flat, and hump-shaped term structures.

\section{B. Constructing the Corporate Bond Yields}

We construct continuously compounded spot rate for each credit rating class using month-end prices on corporate bonds that are either in the Merrill Lynch U.S. Corporate Master Index or the Merrill Lynch U.S. High Yield Index. These indices track the prices of U.S. dollar-denominated investment grade and high yield corporate public debt issued in the U.S. domestic bond market. The Merrill Lynch data set covers the period from January 1997 to June 2004. To construct a long time-series of corporate bond yield sample, we augment the Merrill Lynch data by the Lehman Brothers Fixed Income database from January 1988 to December 1996. The Lehman data covers the period from January 
1973 to March 1998, but there are very few noncallable bonds that were issued before mid 1980s. We estimate our models based on data from January 1988 to October 2004.

We enforce the following bond selection criteria. First, we consider only straight bonds without option features. Callable, putable, convertible and bonds with sinking fund clause are dropped from our sample. Second, bonds with remaining maturities less than one year or greater than 35 years are eliminated. Third, only those bonds that have fixed coupon schedule and pay fixed rate semiannual coupons are included. Fourth, we include only senior unsecured bonds, where bond seniority information are obtained from Moody's Investors Services. Finally, for the Lehman data, bond prices that are calculated using a matrix method are excluded. The resulting bond sample has 337,990 bondmonth observations.

Continuously compounded corporate spot rates for each letter-grade rating class are estimated using the Nelson and Siegel (1987) model and a procedure detailed in Bolder and Streliski (1999). For example, for the AA credit rating class, there are a total of 47031 bond-month observations. The Nelson-Siegel model is estimated for each month on this sub-sample of AA bonds to extract the spot yield curves for the AA credit rating class. We repeat the same procedure for each of the following rating classes: AAA, AA, A, BBB, BB, and $\mathrm{B}$. Yield spread for each rating class is calculated as the difference between the spot yield of the rating class and the maturity-matched Treasury yield. The maturity for the credit spread goes from one to ten years every year.

Table IV reports the summary statistics of credit spreads at different maturities and rating classes. The mean credit spread increases with declining credit ratings. The mean spreads for the three A rating classes are close to one another between 71 and 89 basis points, but the spread increase accelerates as the rating further declines, especially after the rating goes below investment grade. From A to BB, the mean spread almost doubles for each letter downgrade. Across maturities within each rating class, the mean term structure is relatively flat. The standard deviations of credit spreads on AAA, AA, and A bonds are in the same range, but the standard deviation estimates on $\mathrm{BBB}, \mathrm{BB}$, and $\mathrm{B}$ bonds are much larger and increase with declining ratings, more so at short than at long maturities. Credit spreads also show high persistence, more so for high credit rating classes and moderate maturities. 
Figure 3 plots the time series of the credit spreads, with each panel denoting one credit rating class and each line denoting one maturity. We use the same scaling for the four panels on investment-grade spreads (AAA, AA, A, and BBB), but use increasingly larger scales for high yield spreads (BB and B) to accommodate the much wider spreads. Aside from the scale differences, the time series plots in the six panels show common movements that are in line with the state of the economy. For all rating classes, we observe two common periods of high spreads, one in early 1990s and the other in early 2000 , corresponding to the two recessions in our sample period.

[Figure 3 about here.]

Figure 4 plots the term structure of the credit spreads at each month, with the bold solid lines denoting the mean term structure. Although the mean term structures are relatively flat for all six rating classes, the term structure at each month has shown different patterns, including upward sloping, downward sloping, flat, and hump-shaped term structures.

[Figure 4 about here.]

\section{Estimating the No-Arbitrage Links}

For estimation, we cast the dynamic term structure model into a state-space form, extract the distributions of the states at each date by using an efficient filtering technique, and estimate the model using quasi maximum likelihood method, assuming normal forecasting errors on the observed data series.

The statistical dynamics of the three economic factors have already been estimated in the previous sections using the 13 macroeconomic and financial time series, with the estimates reported in Table II. We take these parameter estimates as given and estimate the remaining parameters that determine the no-arbitrage links repeatedly using data from each market.

First, we estimate the market prices of factor risks, and the default-free instantaneous interest rate function using the 12 Treasury spot rate series. Based on this estimation, we determine the impacts of the economic factors on the Treasury yield curve. Then, we re-estimate the market prices of factor 
risks, and also estimate the instantaneous credit spread function at each credit rating group using the ten credit spread series in that rating group. We repeat this estimation procedure for each of the six credit rating classes. The procedure generates seven sets of estimates on the market prices of risks, one set for each market. Market efficiency dictates that different markets should price the same risk the same way. Hence, the seven sets of parameter estimates should be close to one another. Large deviations suggest either market segmentation or model misspecification.

For each estimation, the state propagation equation remains the same as in (3). The difference lies in the different measurement equations. For the Treasury market estimation, the measurement equations are in terms of the continuously compounded Treasury spot rates,

$$
R(t, \tau)=R\left(X_{t}, \tau\right)+e(t, \tau), \quad \tau=0.25,0.5,1,2,3,4,5,6,7,8,9,10 \text { years }
$$

where $e(t, \tau)$ is treated as the measurement error. For estimation on the corporate bond market at a fixed credit rating class $i$, the measurement equations are defined on the credit spreads,

$$
S_{i}(t, \tau)=S_{i}\left(X_{t}, \tau\right)+e_{i}(t, \tau), \quad \tau=1,2,3,4,5,6,7,8,9,10 \text { years }
$$

where $S_{i}\left(X_{t}, \tau\right)$ denotes the spread explained by the three economic factors and $e_{i}(t, \tau)$ denotes the unexplained component, which is treated as the measurement error. To apply Kalman filter, we assume that the measurement errors are normally distributed. We further assume that they are mutually independent but with different variance.

Since the Treasury yields and credit spreads are both affine in the economic factors as shown in equations (20) and (28), respectively, we can use the Kalman filter to obtain the ex ante forecasts and ex post updates on the conditional mean and covariance of the three dynamic factors via the iterative procedure defined by equations (4) to (9). Furthermore, since we have already extracted the dynamic economic factors $X$ in an earlier section from the macroeconomic and financial series, we now regard them as observable series. Hence, the ex post updates are,

$$
\widehat{X}_{t+1}=\widehat{X}_{t+1}^{m} ; \quad \widehat{V}_{t+1}=0,
$$


where $\widehat{X}_{t+1}^{m}$ denotes the dynamic factors extracted in the earlier section. The ex post variance is zero because we treat $\widehat{X}_{t+1}^{m}$ as observable.

The model parameters are estimated by maximizing the log likelihood function defined on the forecasting errors of the Treasury yields and credit spreads, respectively. The procedures estimate the following parameters: $\Theta \equiv\left[a_{r}, b_{r}, \gamma_{0}, \kappa^{\mathbb{Q}}\right]$ and the measurement error variance from the Treasury yields, and $\Theta \equiv\left[a_{i}, b_{i}, \gamma_{0}, \kappa^{\mathbb{Q}}\right]$ and the measurement error variance from the credit spreads of each rating group. Since the bond pricing equations ask for direct input for the risk-neutral mean-reversion coefficient matrix $\kappa^{\mathbb{Q}}=\kappa+\gamma_{1}$. We estimate $\kappa^{\mathbb{Q}}$ directly, instead of estimating the market price coefficient matrix $\gamma_{1}$ and then combining it with the previous estimate on $\kappa$.

\section{Economic Determinants of Treasury and Default Term Structures}

By estimating the dynamic term structure models, we quantify the impacts of each economic factor on the term structure of Treasury yields and credit spreads at different credit rating classes. Furthermore, we link these impacts to the underlying factor dynamics and market prices of factor risks.

\section{A. Predictive Performance of the Economic Factors}

To gauge the performance of the three dynamic economic factors in explaining the variation of the term structure of Treasury and corporate bond yields, Table V reports the predicted variation (PV) of the Treasury yields and corporate bond credit spreads, defined as one minus the ratio of the forecasting error variance over the variance of the Treasury spot rates and corporate credit spreads, respectively.

The model performance is relatively uniform across maturities. The three economic factors predict over 70 percent of the variation in the Treasury yields, and about 30-60 percent of the variation in the corporate credit spreads at the four rating classes. The performance is better than most regression analysis results, showing the enhanced power of prediction in using the dynamic factors extracted from many macroeconomic and financial series, instead of using a few raw series themselves. On the other hand, the results also show that even with the dynamic factor approach, about half of the variation in credit spreads are still not explained by the three major dimensions of the aggregate economy. 


\section{B. Market Prices of Economic Risk}

Table VI reports the estimates and $t$-statistics of the model parameters that determine the market prices of economic factor risks. These market prices, joint with the time series dynamics in Table II, determine the risk-neutral factor dynamics, which play important roles in the Treasury and corporate bond pricing across different maturities.

We estimate the market prices and hence risk-neutral dynamics repeatedly using the term structure of Treasury yields and also the term structure of credit spreads at each of the six credit rating classes. Thus, we obtain seven sets of estimates. Similar estimates across Treasury and the different credit rating classes provide evidence on market integration and the robustness of the dynamic specification. On the other hand, different estimates would suggest either measurement noise or evidence of market segmentation that different markets price the economic risk differently.

The estimates on $\gamma_{0}$ measure the constant portion of the market price. They also define the constant component of the risk-neutral drift of the dynamic factors. Across the five sets of the estimates, the most statistically significant are the negative estimates on the output factor (the second element of $\gamma_{0}$ ), suggesting that the output factor has a negative market price. The estimates on the volatility factor are strongly positive across all five markets, but only one of the five estimates is statistically significant under 95 percent confidence level. The most inconsistent across markets are the estimates on market price of the inflation factor. The market price estimates on the inflation factor are positive for the Treasury and AAA rating class, but negative for the other three rating classes. Nevertheless, four of the five estimates are not significantly different from zero, suggesting large estimation errors on this constant component of market price for inflation risk.

Instead of estimating the proportional component of the market price of risk $\gamma_{1}$ and then deriving the risk-neutral dynamics $\kappa^{\mathbb{Q}}$, we directly set $\kappa^{\mathbb{Q}}$ as the free parameter because it is $\kappa^{\mathbb{Q}}$ that directly enters the bond pricing equation. Overall, the smaller the estimates, the more persistent the economic factors are under the risk-neutral measure, and hence the more long-lasting the factor impacts become.

Table VI shows that the first diagonal element of $\kappa^{\mathbb{Q}}$ is very small, suggesting that the inflation factor is highly persistent under the risk-neutral measure. Hence, shocks on this factor are likely impact 
the term structure of interest rates and credit spreads at both long and short maturities. In contrast, the estimates for the second diagonal element of $\kappa^{\mathbb{Q}}$ are much larger, and all are larger than the time-series counterpart, suggesting that shocks on the real output factor dissipates faster across the term structure than shocks on the inflation risk.

For the third diagonal element of $\kappa^{\mathbb{Q}}$ that controls the risk-neutral persistence and the term structure impact of the volatility factor, the estimate is the largest at 0.7241 from the Treasury market, but the estimates obtained from the corporate bonds markets are smaller, and increasingly so as the credit rating declines. The increasing risk-neutral persistence with declining credit rating dictates that the impact of the volatility factor becomes more long-lasting for corporate bonds at lower credit rating classes.

\section{Economic Determinants of Treasury Yield Term Structure}

Table VII reports the coefficient estimates on the instantaneous default-free interest rate function in the column under "Treasury." The intercept estimate $a_{r}$ measures the long-run mean of the instantaneous default-free interest rate, which has an estimate of 4.86 percent. The loading coefficient estimates, $b_{r}$, measure the contemporaneous response of the short rate to unit shocks on the three macroeconomic and financial factors. The estimates for the three elements are all positive and strongly significant, suggesting that inflation, output, and financial market volatility all have positive impacts on the short rate.

Equation (19) illustrates how the short rate function $\left(a_{r}, b_{r}\right)$ interacts with the risk-neutral factor dynamics $\left(\gamma_{0}, \kappa^{\mathbb{Q}}\right)$ to determine both the mean term structure of Treasury yields, as measured by $a(\tau) / \tau$, and the factor loadings across the term structure, as measured by $b(\tau) / \tau$. Figure 5 plots the mean term structure in the left panel and loadings of the three factors in the right panel. The upward sloping mean term structure in the left panel is consistent with data observation. The three lines in the right panel show the contemporaneous response of the Treasury yield curve to unit shocks on the three economic factors, respectively. The solid line denotes the response to the inflation factor, which is positive and the strongest among the three lines. Furthermore, the response is large not only at short maturities, but also lasts through long maturities due to the high risk-neutral persistence of the inflation factor. 
[Figure 5 about here.]

The dashed line denotes the impacts of the real output factor, which is also positive, but smaller in magnitude. Furthermore, due to the lower risk-neutral persistence of this real output factor, the impacts dissipate faster as maturity increases. For a unit shock to the real output factor, the response of one-year Treasury rate is about twice as much as the response of the ten-year Treasury rate.

Finally, the dash-dotted line captures the impacts of the financial market volatility factor, which are positive but small in magnitudes. Furthermore, its impacts also decline quickly with increasing maturities. The impacts are close to zero at long maturities.

Factor analysis on the term structure of interest rates, e.g., Litterman and Scheinkman (1991), Knez, Litterman, and Scheinkman (1994), and Heidari and Wu (2003), identifies three key factors, which are often referred to as the level factor, the slope factor, and the curvature factor, respectively. $\mathrm{Lu}$ and $\mathrm{Wu}$ (2004) show that the inflation factor and the output factor generate a level and slope effect on the term structure, respectively, which match the role of the first two statistical factors. Heidari and Wu (2003) show that the third statistical factor in interest rates is highly correlated with the interest rate option implied volatilities. Our proposed three-dimensional decomposition of the aggregate economy is in line with such evidence. The factor loading plots in Figure 5 also reveal similar interpretations for the three economic factors.

\section{Economic Determinants of Credit Spread Term Structure}

Table VII also reports the parameter estimates for the instantaneous credit spread function under each of the six credit rating classes. The estimates for $a_{i}$ measure the fixed component of the instantaneous spread induced by credit risk. The estimate for this intercept is close to zero for AAA bonds, but becomes increasingly positive as the rating declines, indicating an increased average compensation for the increased risk at lower credit rating classes.

The loading coefficient estimates on the three economic factors vary across different rating classes.

These loading coefficients interact with the risk-neutral factor dynamics $\kappa^{\mathbb{Q}}$ to determine how shocks 
in the three factors impact the term structure of corporate bond yields and hence the credit spreads. Figure 6 plots the three elements of $\left(b_{i}(\tau)-b(\tau)\right) / \tau$ for each credit rating group, which measure the contemporaneous responses of the credit spread term structure to unit shocks on each of the three dynamic economic factors. The responses are computed according to (28) and the ordinary differential equations in (19) and (25). Each panel in Figure 6 corresponds to one rating class and each line corresponds to the response of the credit spread term structure to one of the three economic factors. For ease of comparison, we use the same scale for the four investment grade panels (AAA, AA, A, and $\mathrm{BBB})$. We use a larger scale for the high-yield panels (BB and $\mathrm{B}$ ) to accommodate the larger responses.

\section{[Figure 6 about here.]}

The solid line in each panel denotes the response of the credit spread term structures to the inflation factor. The responses are positive across all rating groups. Within each rating group, the responses are persistent across maturities, consistent with its persistent risk-neutral dynamics. The positive responses suggest that increasing inflation not only increases the Treasury rate across all maturities, but also widens the credit spreads on corporate bonds.

The dashed line in each panel shows the response of the credit spread term structure to the real output factor. The responses are slightly positive for AAA and AA credit spreads, but become negative for A credit spreads, and very much so for the BBB, BB, and B credit rating classes. Furthermore, the negative responses are larger at short maturities than at long maturities. Thus, although a positive output shock increases the interest rate level and flattens an otherwise upward sloping yield curve, it reduces the pricing and/or risk of corporate default and narrows the credit spread at low credit rating classes, particularly so at short maturities.

The dash-dotted line in each panel plots the response of the credit spreads to the financial market volatility factor. The responses are positive for all rating groups, and increasingly so with declining credit ratings. Furthermore, in all cases, the impacts increase with maturities, consistent with the high risk-neutral persistence for this volatility factor estimated from the corporate bond market. Therefore, whereas the Treasury yields are dominated by macroeconomic forces, the financial market volatility 
plays an increasingly important role on the credit spreads, particularly at low rating classes and long maturities.

\section{Credit Spreads Term Structure For Financial and Corporate Sectors}

To investigate whether corporate bond spreads at different industry sectors react differently to the economic shocks, we further divide the corporate bonds sample within each credit rating class into two broad industry sectors: financial $(\mathrm{F})$ and corporate $(\mathrm{C})$. We construct the term structure of credit spreads for each industry sector and rating class, with the exception of BB and B rating classes, where lack of data prevent us from obtaining reliable term structure estimates for the two industry sectors.

Figure 7 compares the time series of the credit spreads for these two industry sectors under each of the four rating classes. The common movements are similar to what we have observed from the aggregate plots in Figure 3. Comparing the time series between the two industry sectors within each credit rating class, we find that the credit spreads are slightly higher for the financial firms than for the corporate firms.

[Figure 7 about here.]

We repeat the estimation on each of eight new classifications of credit spreads. The parameter estimates are roughly in the same range as those obtained before. o save space, we do not report the parameter estimates. They are available upon request. Figure 8 plots the contemporaneous response of the credit spreads to unit shocks on the three economic factors. We apply the same scale to all panels for ease of comparison. As before, we find that the the inflation factor has positive and persistent impacts on the term structure of credit spreads, but the impacts become smaller at lower credit ratings. The real output factor has slightly positive impacts on credit spreads at high credit rating classes, but the impacts become negative at lower rating classes. The impact of the volatility factor is small at high rating classes, but becomes strongly positive at long rating classes.

[Figure 8 about here.] 
Comparing the responses between the two industry sectors within each rating class, we find that the responses of the credit spreads in the financial sector are stronger in absolute magnitudes than the response of the spreads in the corporate sector, especially at lower rating classes. For the financial sector, the impacts of the inflation factor are more positive across all rating classes; the impacts of the real output factor are more negative for the BBB class; and the impacts of the volatility factor more positive for AA, A, and BBB classes. Therefore, overall the financial sector is more sensitive to changes in the economic environments.

\section{Conclusion}

We use a dynamic factor model to summarize the information in many observed macroeconomic and financial data series and to provide a no-arbitrage link between the dynamic economic factors and the term structure of Treasury yields and credit spreads of corporate bonds at different credit rating classes and industry sectors. By estimating the model, we quantify the impacts of many macroeconomic and financial series on the whole term structure of Treasury yields and credit spreads. We also learn the fundamental sources behind the impacts: the economic factor dynamics and market prices of economic risks.

We find that positive inflation shocks increase Treasury yields and credit spreads across all maturities and credit rating classes. The impacts on the Treasury yields are the strongest. The impacts on the credit spreads are smaller, and decline with lowering credit ratings. Thus, a positive inflation shock moves up both the benchmark yield curve and the credit spread, more so for the Treasury rates and spreads on high credit rating classes than for the spreads on low rating classes.

Positive shocks on the real output growth also increase the Treasury yields, more so at short maturities than at long maturities. The impacts on the credit spreads are positive for high credit rating classes, but become negative and increasingly so as we move to lower credit rating classes. Furthermore, the impacts are more negative at shorter maturities than at longer maturities. Thus, a positive shock to the real side of the economy increases the benchmark interest-rate level, flattens an otherwise upward sloping yield curve, but narrows the credit spread, particularly at short maturities and low credit rating classes. 
The financial market volatility factor has small and transient impacts on the Treasury yield curve, but strongly positive and persistent impacts on the credit spreads across the whole term structure. Therefore, although increasing financial market volatility has only small impact on the benchmark yield curve, it widens the credit spread, more so at long maturities and low rating classes.

When we further decompose each credit rating class into two industry sectors: financial and corporate, we find that the credit spreads in the financial sectors are on average wider and more volatile than the spreads in the corporate sector, especially at lower rating groups. Furthermore, the credit spreads in the financial sector also respond more strongly to changes in economic climates.

This paper integrates the strength of two strands of extant literature: the economic intuition of regression analysis on observed variables and the internal consistency of the dynamic term structure modeling. Our results show great synergy from the integration, and abundant potential for future research. First, a dynamic factor model can be used in many research areas as an efficient way to reduce noise and strengthen the signal content of many explanatory variable choices. Instead of choosing one over another, a dynamic factor model allows us to include them all, with the information filtered out from the factors. This approach becomes more important with the increasing availability of large amounts of data. Second, no-arbitrage arguments can be used to add discipline, economic rigor, and internal consistency in many applications of factor analyses. The no-arbitrage modeling literature is long and well established, but linking it to observable economic fundamentals is only at its nascent stage, leaving wide open opportunities for future explorations, not only for linkages between interest rates/exchange rates and aggregate economic factors, but also for linkages between corporate bonds/stocks and firm level fundamentals. 


\section{REFERENCES}

Altman, Edward I., Brooks Brady, Andrea Resti, and Andrea Sironi, 2004, The link between default and recovery rates: Theory, empirical evidence and implications, Journal of Business forthcoming.

Bakshi, Gurdip, Dilip Madan, and Frank Zhang, 2004, Investigating the role of systematic and firmspecific factors in default risk: Lessons from empirically evaluating credit risk models, Journal of Business forthcoming.

Bangia, Anil, Francis X. Diebold, Andr Kronimus, Christian Schagen, and Til Schuermann, 2002, Ratings migration and the business cycle, with application to credit portfolio stress testing, Journal of Banking and Finance 26, 445-474.

Bevan, Andrew, and Francesco Garzarelli, 2000, Corporate bond spreads and the business cycle: Introducing gs-spread, Journal of Fixed Income 9, 8-18.

Black, Fischer, and Myron Scholes, 1973, The pricing of options and corporate liabilities, Journal of Political Economy 81, 637-654.

Bolder, David, and David Streliski, 1999, Yield curve modelling at the bank of canada, Working paper, Bank of Canada.

Carey, Mark, 1998, Credit risk in private debt portfolios, Journal of Finance 53, 1363-1387.

Carr, Peter, and Liuren Wu, 2004, A tale of two indices, Working paper, Bloomberg LP and Baruch College.

Collin-Dufresne, Pierre, Robert S. Goldstein, and Jean Helwege, 2003, Is credit event risk priced? modeling contagion via the updating of beliefs, Working paper, Washington University St. Louis.

Collin-Dufresne, Pierre, Robert S. Goldstein, and J. Spencer Martin, 2001, The determinants of credit spread changes, Journal of Finance 56, 2177-2207.

Delianedis, Gordon, and Robert Geske, 2001, The components of corporate credit spreads: Default, recovery, tax, jumps, liquidity, and marker factors, Working paper, UCLA.

Duffee, Gregory, 1999, Estimating the price of default risk, Review of Financial Studies 12, 197-226. 
Duffie, Darrell, and Rui Kan, 1996, A yield-factor model of interest rates, Mathematical Finance 6, $379-406$.

Duffie, Darrell, Jun Pan, and Kenneth Singleton, 2000, Transform analysis and asset pricing for affine jump diffusions, Econometrica 68, 1343-1376.

Duffie, Darrel, Lasse Heje Pedersen, and Kenneth J. Singleton, 2003, Modeling sovereign yield spreads: A case study of russian debt, Journal of Finance 58, 119-160.

Duffie, Darrel, and Kenneth Singleton, 1997, An econometric model of the term structure of interest rate swap yields, Journal of Finance 52, 1287-1322.

Duffie, Darrel, and Kenneth J. Singleton, 1999, Modeling term structure of defaultable bonds, Review of Financial Studies 12, 687-720.

Elton, Edwin J., Martin J. Gruber, Deepak Agrawal, and Christopher Mann, 2001, Explaining the rate spread on corporate bonds, Journal of Finance 56, 247-277.

Engle, Robert, 2004, Risk and volatility: Econometric models and financial practice, American Economic Review 94, 405-420.

Eom, Young Ho, Jean Helwege, and Jing-zhi Huang, 2003, Structural models of corporate bond pricing, Review of Financial Studies forthcoming.

Frye, Jon, 2000, Depressing recoveries, Risk October, 108-111.

Heidari, Massoud, and Liuren $\mathrm{Wu}, 2003$, Are interest rate derivatives spanned by the term structure of interest rates?, Journal of Fixed Income 13, 75-86.

Huang, Jing-zhi, and Ming Huang, 2003, How much of the corporate-Treasury yield spread is due to credit risk?, Working paper, Penn State University.

Jones, E. Philip, Scott P. Mason, and Eric Rosenfeld, 1984, Contingent claim analysis of corporate capital structures: An empirical investigation, Journal of Finance 39, 611-625.

Knez, Peter J., Robert Litterman, and Jose Scheinkman, 1994, Explorations into factors explaining money market returns, Journal of Finance 49, 1861-1882.

Litterman, Robert, and Jose Scheinkman, 1991, Common factors affecting bond returns, Journal of Fixed Income 1, 54-61. 
Liu, Jun, Francis A. Longstaff, and Ravit E. Mandell, 2000, The market price of credit risk: An empirical analysis of interest rate swap spreads, Working paper, UCLA.

Longstaff, Francis A., Sanjay Mithal, and Eric Neis, 2004, Corporate yield spreads: Default risk or liquidity? new evidence from the credit-default swap market, Working paper, UCLA.

Longstaff, Francis A., and E.S. Schwartz, 1995, A simple approach to valuing risky fixed and floating rate debt, Journal of Finance 50, 789-819.

Lu, Biao, and Liuren Wu, 2004, Systematic macroeconomic movements and the term structure of interest rates, Working paper, Baruch College.

Merton, Robert C., 1974, On the pricing of corporate debt: The risk structure of interest rates, Journal of Finance 29, 449-470.

Nelson, Charles R., and Andrew F. Siegel, 1987, Parsimonious modeling of yield curves, Journal of Business 60, 473-489.

Nickell, Pamela, William Perraudin, and Simone Varotto, 2000, Stability of rating transitions, Journal of Banking and Finance 24, 203-227.

Pedrosa, Monica, and Richard Roll, 1998, Systematic risk in corporate bond yields, Journal of Fixed Income 8, 7-2.

Sargent, Thomas, 1989, Two models of measurements and investment accelerator, Journal of Political Economy 97, 251-287.

Sargent, Thomas, and Christopher A. Sims, 1977, Business cycle modeling without pretending to have too much a-priori economic theory, C. sims et al., eds., new methods in business cycle research, Federal Reserve Bank of Minneapolis.

Stock, James H., and Mark W. Watson, 1989, New indexes of coincident and leading economic indicators, NBER Macroeconomic Annual pp. 351-393.

Svensson, Lars E. O., 1995, Estimating forward interest rates with the extended Nelson \& Siegel method, Quarterly Review, Sveriges Riksbank 3, 13-26.

Woodford, Micahel, 2003, Interest and Prices. (Princeton University Press Princeton, New Jersey). 
Table I

\section{Extracting Systematic Dynamic Factors From Macroeconomic and Financial Data}

Entries report the estimates and the absolute values of the $t$-statistics (in parentheses) of parameters $(H)$ that link each observed data series to the three systematic dynamic factors. Entries under $H_{i}$ denote the loadings of each series on the $i$ th factor. Entries under $R^{y}$ report the measurement error variance estimates and $t$-statistics for each series. The last column (PV) reports the predicted variation of the factors on each series, defined as one minus the ratio of the forecasting error variance over the variance of the original series. The parameters are estimated with maximum likelihood method and Kalman filtering using macroeconomic and financial data series listed below. The macroeconomic data are from the Federal Reserve Board, the volatility series are downloaded from Bloomberg. The sample period is from January 1988 to June 2004.

\begin{tabular}{lccccccccc}
\hline Series & \multicolumn{2}{c}{$H_{1}$} & \multicolumn{2}{c}{$H_{2}$} & \multicolumn{2}{c}{$H_{3}$} & \multicolumn{2}{c}{$\mathcal{R}^{y}$} & $\mathrm{PV}$ \\
\hline CPI & 0.439 & $(6.45)$ & - & - & - & - & 0.081 & $(4.20)$ & 0.891 \\
Core CPI & 0.415 & $(4.06)$ & - & - & - & - & 0.181 & $(4.80)$ & 0.841 \\
PPI & 0.316 & $(2.92)$ & - & - & - & - & 0.523 & $(3.58)$ & 0.424 \\
Core PPI & 0.403 & $(7.45)$ & - & - & - & - & 0.224 & $(8.39)$ & 0.767 \\
PCE Deflator & 0.454 & $(8.47)$ & - & - & - & - & 0.020 & $(4.47)$ & 0.949 \\
Core PCE Deflator & 0.424 & $(4.44)$ & - & - & - & - & 0.143 & $(3.67)$ & 0.857 \\
GDP deflator & 0.437 & $(7.81)$ & - & - & - & - & 0.085 & $(4.40)$ & 0.929 \\
Real GDP & - & - & 0.277 & $(5.67)$ & - & - & 0.399 & $(4.48)$ & 0.571 \\
Industrial Production & - & - & 0.299 & $(8.43)$ & - & - & 0.314 & $(7.89)$ & 0.641 \\
Non-farm Payrolls & 0.169 & $(4.50)$ & 0.379 & $(10.7)$ & - & - & $0.000(0.00)$ & 0.988 \\
Real PCE & - & - & 0.228 & $(6.89)$ & - & - & 0.548 & $(7.32)$ & 0.449 \\
VXO & - & - & - & - & 0.391 & $(14.0)$ & 0.000 & $(0.00)$ & 0.987 \\
VIX & - & - & - & - & 0.379 & $(13.6)$ & 0.020 & $(4.60)$ & 0.974 \\
\hline
\end{tabular}


Table II

\section{Time Series Dynamics of the Economic Factors}

Entries report the parameter estimates and the absolute values of the $t$-statistics (in parentheses) on timeseries dynamics of the three economic factors. The dynamics are estimated with maximum likelihood method and Kalman filtering with 13 macroeconomic and financial data series. The macroeconomic

data are from the Federal Reserve Board. The volatility series are downloaded from Bloomberg. The data are monthly from January 1988 to June 2004.

\begin{tabular}{llcc}
\hline Dynamic Factors $(X)$ & \multicolumn{2}{l}{$\kappa$ in: $d X=-\kappa X d t+d W$} & \\
\hline Inflation & 0.1139 & 0 & - \\
Real Output & $(0.62)$ & - & 0.2007 \\
Volatility & 0.4891 & $(1.58)$ & - \\
& $(2.71)$ & -0.1790 & 0.0625 \\
& 0.1484 & $(1.42)$ & $(0.49)$ \\
\hline
\end{tabular}




\section{Table III \\ Summary Statistics of Treasury Yields}

Entries report mean ('Mean'), standard deviation ('Std'), skewness ('Skew'), kurtosis ('Kurt'), and monthly autocorrelation ('Auto') of the continuously compounded Treasury yields at different maturities. Data are monthly from January 1988 to June 2004, obtained from the Federal Reserve Board.

\begin{tabular}{llrrrr}
\hline Maturity & Mean & Std & Skew & Kurt & Auto \\
\hline $3 \mathrm{~m}$ & 4.777 & 2.081 & -0.120 & -0.580 & 0.986 \\
$6 \mathrm{~m}$ & 4.887 & 2.114 & -0.183 & -0.571 & 0.986 \\
$1 \mathrm{y}$ & 5.083 & 2.090 & -0.244 & -0.525 & 0.985 \\
$2 \mathrm{y}$ & 5.395 & 1.953 & -0.273 & -0.438 & 0.981 \\
$3 \mathrm{y}$ & 5.636 & 1.821 & -0.246 & -0.417 & 0.978 \\
$4 \mathrm{y}$ & 5.833 & 1.715 & -0.195 & -0.457 & 0.976 \\
$5 \mathrm{y}$ & 6.002 & 1.632 & -0.135 & -0.531 & 0.975 \\
$6 \mathrm{y}$ & 6.149 & 1.565 & -0.074 & -0.618 & 0.974 \\
$7 \mathrm{y}$ & 6.278 & 1.510 & -0.016 & -0.702 & 0.973 \\
$8 \mathrm{y}$ & 6.391 & 1.464 & 0.037 & -0.775 & 0.973 \\
$9 \mathrm{y}$ & 6.491 & 1.424 & 0.085 & -0.835 & 0.973 \\
$10 \mathrm{y}$ & 6.578 & 1.389 & 0.126 & -0.883 & 0.973 \\
\hline
\end{tabular}




\section{Table IV}

\section{Summary Statistics of Credit Spreads on Corporate Bonds}

Entries report mean, standard deviation, and monthly autocorrelation of the credit spreads on corporate bonds at each maturity and credit rating class. The spreads are defined as the difference in percentage points between continuously compounded spot rates at a certain credit rating group and the corresponding Treasury spot rates. Corporate bond spot rates are extracted using Nelson-Siegel method from the corporate bond data. Data are monthly from January 1988 to June 2004, obtained from the Federal Reserve Board and Merrill Lynch.

\begin{tabular}{|c|c|c|c|c|c|c|c|c|c|c|}
\hline Maturity & 1 & 2 & 3 & 4 & 5 & 6 & 7 & 8 & 9 & 10 \\
\hline & \multicolumn{10}{|c|}{ Sample Mean } \\
\hline AAA & 0.714 & 0.713 & 0.735 & 0.754 & 0.762 & 0.760 & 0.751 & 0.737 & 0.720 & 0.703 \\
\hline AA & 0.749 & 0.747 & 0.772 & 0.800 & 0.821 & 0.833 & 0.837 & 0.836 & 0.830 & 0.823 \\
\hline A & 0.890 & 0.937 & 0.993 & 1.039 & 1.070 & 1.088 & 1.096 & 1.095 & 1.090 & 1.081 \\
\hline BBB & 1.519 & 1.472 & 1.480 & 1.509 & 1.539 & 1.565 & 1.584 & 1.598 & 1.606 & 1.611 \\
\hline $\mathrm{BB}$ & 3.828 & 3.320 & 3.079 & 2.985 & 2.969 & 2.990 & 3.027 & 3.067 & 3.104 & 3.136 \\
\hline \multirow[t]{2}{*}{ B } & 6.068 & 6.389 & 6.456 & 6.362 & 6.191 & 5.984 & 5.762 & 5.531 & 5.297 & 5.061 \\
\hline & \multicolumn{10}{|c|}{ Sample Standard Deviation } \\
\hline AAA & 0.392 & 0.298 & 0.290 & 0.302 & 0.311 & 0.314 & 0.315 & 0.315 & 0.315 & 0.315 \\
\hline AA & 0.263 & 0.255 & 0.270 & 0.280 & 0.288 & 0.295 & 0.303 & 0.311 & 0.320 & 0.330 \\
\hline $\mathrm{A}$ & 0.305 & 0.327 & 0.346 & 0.350 & 0.350 & 0.348 & 0.348 & 0.351 & 0.356 & 0.362 \\
\hline BBB & 0.555 & 0.606 & 0.621 & 0.614 & 0.596 & 0.575 & 0.555 & 0.538 & 0.526 & 0.517 \\
\hline BB & 2.167 & 1.508 & 1.241 & 1.143 & 1.109 & 1.102 & 1.114 & 1.138 & 1.170 & 1.207 \\
\hline \multirow[t]{2}{*}{ B } & 4.789 & 4.232 & 4.184 & 4.030 & 3.734 & 3.355 & 2.942 & 2.531 & 2.157 & 1.863 \\
\hline & \multicolumn{10}{|c|}{ Monthly Autocorrelation } \\
\hline AAA & 0.920 & 0.949 & 0.966 & 0.971 & 0.972 & 0.972 & 0.972 & 0.970 & 0.967 & 0.963 \\
\hline $\mathrm{AA}$ & 0.908 & 0.940 & 0.951 & 0.956 & 0.960 & 0.963 & 0.965 & 0.966 & 0.965 & 0.964 \\
\hline A & 0.925 & 0.954 & 0.960 & 0.962 & 0.963 & 0.963 & 0.964 & 0.964 & 0.963 & 0.962 \\
\hline BBB & 0.916 & 0.955 & 0.965 & 0.968 & 0.968 & 0.968 & 0.967 & 0.966 & 0.964 & 0.962 \\
\hline $\mathrm{BB}$ & 0.813 & 0.891 & 0.926 & 0.927 & 0.924 & 0.924 & 0.926 & 0.926 & 0.924 & 0.920 \\
\hline B & 0.660 & 0.833 & 0.911 & 0.932 & 0.936 & 0.935 & 0.931 & 0.925 & 0.913 & 0.891 \\
\hline
\end{tabular}


Table V

Predictive Power of the Dynamic Economic Factors on the Term Structure of Treasury Yields and Credit Spreads

Entries report the predicted variation (PV) of the dynamic factors on the Treasury yields and and corporate credit spreads, defined as one minus the ratio of the forecasting error variance to the variance of the Treasury spot rate and corporate credit spread, respectively. Treasury yields and credit spreads at each rating classes are forecasted by three economic factors according to a no-arbitrage dynamic term structure model. The forecasts are made according to the estimated factor dynamics.

\begin{tabular}{lcccccccccc}
\hline Maturity & 1 & 2 & 3 & 5 & 5 & 6 & 7 & 8 & 9 & 10 \\
\hline Treasury & 0.754 & 0.739 & 0.725 & 0.719 & 0.718 & 0.720 & 0.721 & 0.721 & 0.720 & 0.718 \\
AAA & 0.224 & 0.564 & 0.672 & 0.644 & 0.594 & 0.548 & 0.511 & 0.484 & 0.467 & 0.457 \\
AA & 0.436 & 0.544 & 0.525 & 0.477 & 0.426 & 0.387 & 0.365 & 0.356 & 0.352 & 0.346 \\
A & 0.406 & 0.535 & 0.511 & 0.477 & 0.442 & 0.411 & 0.385 & 0.367 & 0.354 & 0.343 \\
BBB & 0.389 & 0.585 & 0.643 & 0.658 & 0.649 & 0.626 & 0.594 & 0.559 & 0.522 & 0.486 \\
BB & 0.329 & 0.470 & 0.492 & 0.464 & 0.457 & 0.479 & 0.516 & 0.553 & 0.582 & 0.600 \\
B & 0.338 & 0.581 & 0.591 & 0.561 & 0.539 & 0.529 & 0.525 & 0.521 & 0.506 & 0.460 \\
& & & & & & & & & & \\
\hline
\end{tabular}


Table VI

Market Prices of Economic Risk

Entries report the parameter estimates and absolute magnitudes of the $t$-statistics (in parentheses) on market prices of economic factor risks that, joint with the time series dynamics in Table II, determine the risk-neutral factor dynamics. The parameters are estimated from Treasury yields and corporate credit spreads at each of the six credit rating classes. $\gamma_{0}$ denotes the constant component of the market price of the factor risks, which determines the constant component of the risk-neutral drift of the factors. $\kappa^{\mathbb{Q}}=\kappa+\gamma_{1}$ defines the mean-reverting property of the dynamic factors under the risk-neutral measure, with $\gamma_{1}$ denoting the proportional component of the market prices. The parameters are estimated with maximum likelihood methods, using Treasury yields and corporate bond credit spreads, respectively. Data are from the Federal Reserve Board and Merrill Lynch, monthly from January 1988 to June 2004.

\begin{tabular}{|c|c|c|c|c|c|c|c|}
\hline \multicolumn{3}{|c|}{$\gamma_{0}$} & \multicolumn{4}{|c|}{$\kappa^{\mathbb{Q}}$} & \\
\hline \multicolumn{8}{|c|}{ Treasury Yield } \\
\hline 0.0115 & $(0.08)$ & 0.0117 & $(0.13)$ & 0 & - & 0 & - \\
\hline-1.7951 & ( 2.32 ) & 0.3328 & $(0.66)$ & 0.3481 & ( 9.22 ) & 0 & - \\
\hline 3.5003 & $(1.42)$ & -0.9021 & $(0.54)$ & -0.1689 & $(0.63)$ & 0.7241 & $(12.5)$ \\
\hline \multicolumn{8}{|c|}{ Credit rating group: AAA } \\
\hline 0.1009 & $(0.15)$ & 0.0022 & $(0.17)$ & - & - & - & - \\
\hline-3.5325 & ( 6.52 ) & 0.2862 & ( 1.41$)$ & 1.1672 & ( 4.46 ) & - & - \\
\hline 4.9724 & $(0.82)$ & -0.1839 & $(0.36)$ & -2.2665 & ( 3.71$)$ & 0.1022 & ( 10.29$)$ \\
\hline \multicolumn{8}{|c|}{ Credit rating group: AA } \\
\hline-1.2959 & $(10.56)$ & 0.1038 & $(9.16)$ & - & - & - & - \\
\hline-1.5492 & $(4.55)$ & -0.0464 & $(0.49)$ & 0.4035 & ( 5.20$)$ & - & - \\
\hline 7.9824 & $(20.38)$ & -0.0720 & $(0.51)$ & -0.3207 & ( 1.89$)$ & 0.0959 & ( 10.11$)$ \\
\hline \multicolumn{8}{|c|}{ Credit rating group: A } \\
\hline-0.2805 & $(0.19)$ & 0.0877 & $(0.09)$ & - & - & - & - \\
\hline-1.9276 & $(0.57)$ & 0.0683 & $(0.03)$ & 0.3890 & ( 1.89$)$ & - & - \\
\hline 2.9054 & $(0.17)$ & -0.2062 & $(0.02)$ & -0.1850 & $(0.42)$ & 0.1636 & $(7.55)$ \\
\hline \multicolumn{8}{|c|}{ Credit rating group: BBB } \\
\hline-0.4496 & $(0.42)$ & 0.0495 & $(0.11)$ & - & - & - & - \\
\hline-2.5961 & ( 1.08 ) & 0.1104 & $(0.06)$ & 1.5610 & $(0.89)$ & - & - \\
\hline 3.0067 & $(0.41)$ & -0.0113 & $(0.00)$ & -1.3348 & $(0.69)$ & 0.1651 & $(5.50)$ \\
\hline \multicolumn{8}{|c|}{ Credit rating group: BB } \\
\hline-0.9907 & $(0.69)$ & 0.0054 & $(0.32)$ & - & - & - & - \\
\hline-0.8301 & $(0.13)$ & 1.0995 & $(0.56)$ & 0.2557 & $(0.33)$ & - & - \\
\hline 3.6565 & $(0.63)$ & -0.6077 & $(0.71)$ & 0.0180 & $(0.05)$ & 0.0178 & $(0.42)$ \\
\hline \multicolumn{8}{|c|}{ Credit rating group: $\mathrm{B}$} \\
\hline-0.8123 & $(0.17)$ & 0.0042 & ( 2.99 ) & - & - & - & - \\
\hline-1.9412 & $(0.16)$ & 0.9220 & $(1.16)$ & 0.4502 & $(0.63)$ & - & - \\
\hline 3.2056 & $(0.18)$ & 0.7934 & ( 4.91$)$ & -0.1414 & $(0.98)$ & 0.0054 & ( 1.08$)$ \\
\hline
\end{tabular}


Table VII

The Instantaneous Default-Free Interest Rate and Credit Spread Functions

Entries report the parameter estimates and absolute magnitudes of the $t$-statistics (in parentheses) on the instantaneous default-free interest rate function and the instantaneous credit spread function under different rating classes. The parameter $a_{r}$ and $a_{i}$ re the corresponding intercepts and $b_{r}$ and $b_{i}$ are the corresponding loading vector on each of the three factors. The parameters are estimated with maximum likelihood methods and Kalman filter, using corporate bond yield spreads over the corresponding Treasury yield at maturities from one to ten years. Data are monthly from January 1988 to June 2004, obtained from the Federal Reserve Board and Merrill Lynch.

\begin{tabular}{|c|c|c|c|c|c|c|c|}
\hline Ratings & Treasury & AAA & AA & $\mathrm{A}$ & BBB & $\mathrm{BB}$ & B \\
\hline Intercepts $\left(a_{r} / a_{i}\right)$ & $\begin{array}{l}0.0486 \\
(56.3)\end{array}$ & $\begin{array}{l}0.0000 \\
(0.88)\end{array}$ & $\begin{array}{l}0.0053 \\
(7.42)\end{array}$ & $\begin{array}{l}0.0063 \\
(4.23)\end{array}$ & $\begin{array}{l}0.0100 \\
(1.91)\end{array}$ & $\begin{array}{l}0.0345 \\
(2.98)\end{array}$ & $\begin{array}{l}0.0724 \\
(0.29)\end{array}$ \\
\hline \multicolumn{8}{|c|}{ Factor Loadings $\left(b_{r} / b_{i}\right)$ : } \\
\hline Inflation & $\begin{array}{l}0.0107 \\
(18.1)\end{array}$ & $\begin{array}{l}0.0020 \\
(4.11)\end{array}$ & $\begin{array}{l}0.0011 \\
(4.88)\end{array}$ & $\begin{array}{l}0.0011 \\
(1.25)\end{array}$ & $\begin{array}{l}0.0007 \\
(0.23)\end{array}$ & $\begin{array}{c}-0.0008 \\
(0.41)\end{array}$ & $\begin{array}{l}0.0070 \\
(2.24)\end{array}$ \\
\hline Real Output & $\begin{array}{l}0.0073 \\
(23.8)\end{array}$ & $\begin{array}{l}0.0014 \\
(2.01)\end{array}$ & $\begin{array}{l}0.0002 \\
(1.20)\end{array}$ & $\begin{array}{r}-0.0001 \\
(0.50)\end{array}$ & $\begin{array}{l}0.0012 \\
(0.29)\end{array}$ & $\begin{array}{r}-0.0052 \\
(5.86)\end{array}$ & $\begin{array}{l}-0.0126 \\
(4.54)\end{array}$ \\
\hline Volatility & $\begin{array}{l}0.0025 \\
(31.1)\end{array}$ & $\begin{array}{l}-0.0006 \\
(12.69)\end{array}$ & $\begin{array}{l}-0.0006 \\
(10.93)\end{array}$ & $\begin{array}{r}-0.0002 \\
(2.29)\end{array}$ & $\begin{array}{l}0.0002 \\
(1.34)\end{array}$ & $\begin{array}{l}-0.0005 \\
(1.77)\end{array}$ & $\begin{array}{l}0.0006 \\
(4.57)\end{array}$ \\
\hline
\end{tabular}




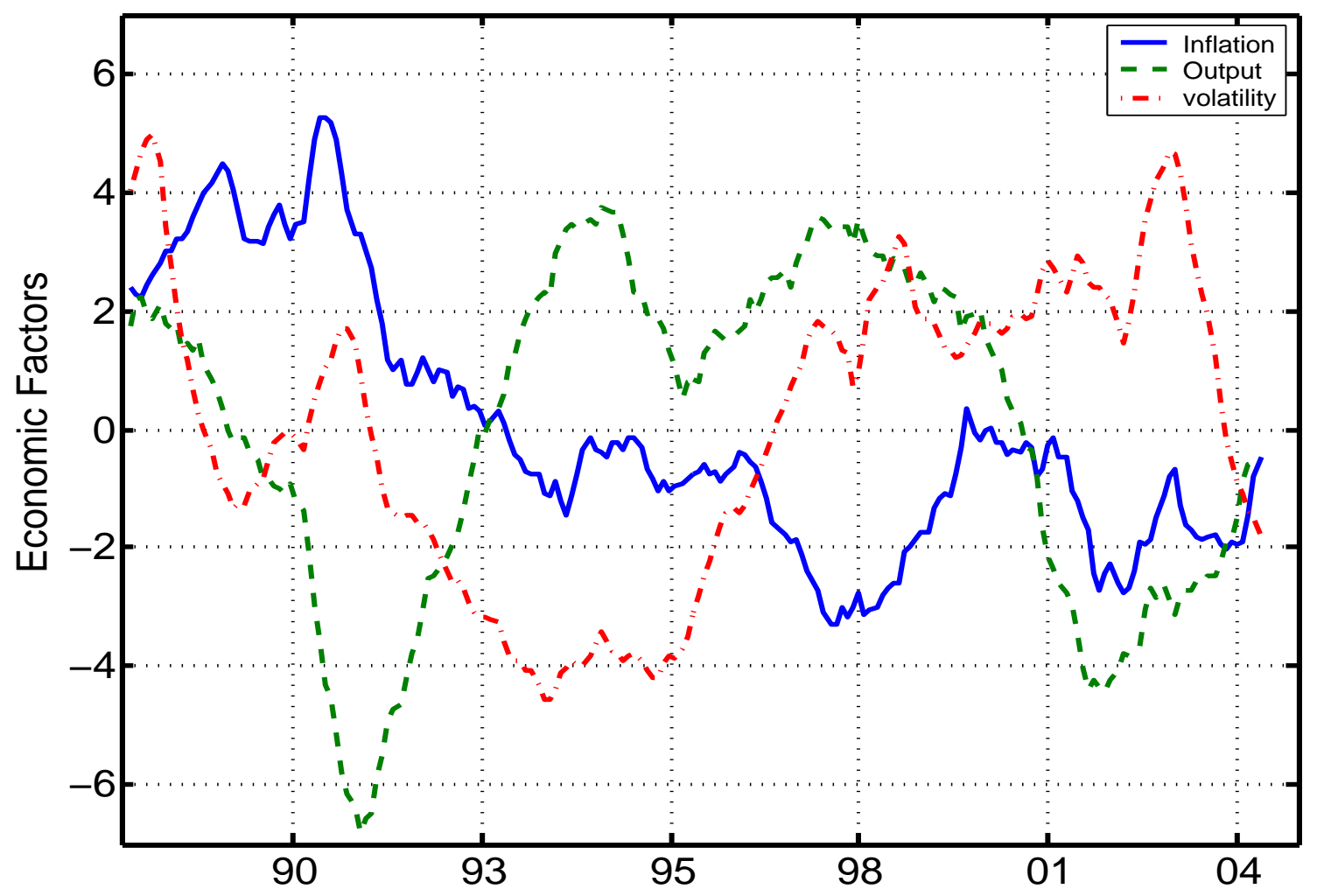

Figure 1. Time series dynamics of economic factors. The solid line denotes the time series of the extracted inflation factor, the dashed line denotes the time series of the extracted real output growth factor, and the dash-dotted line denotes the financial market volatility factor. 

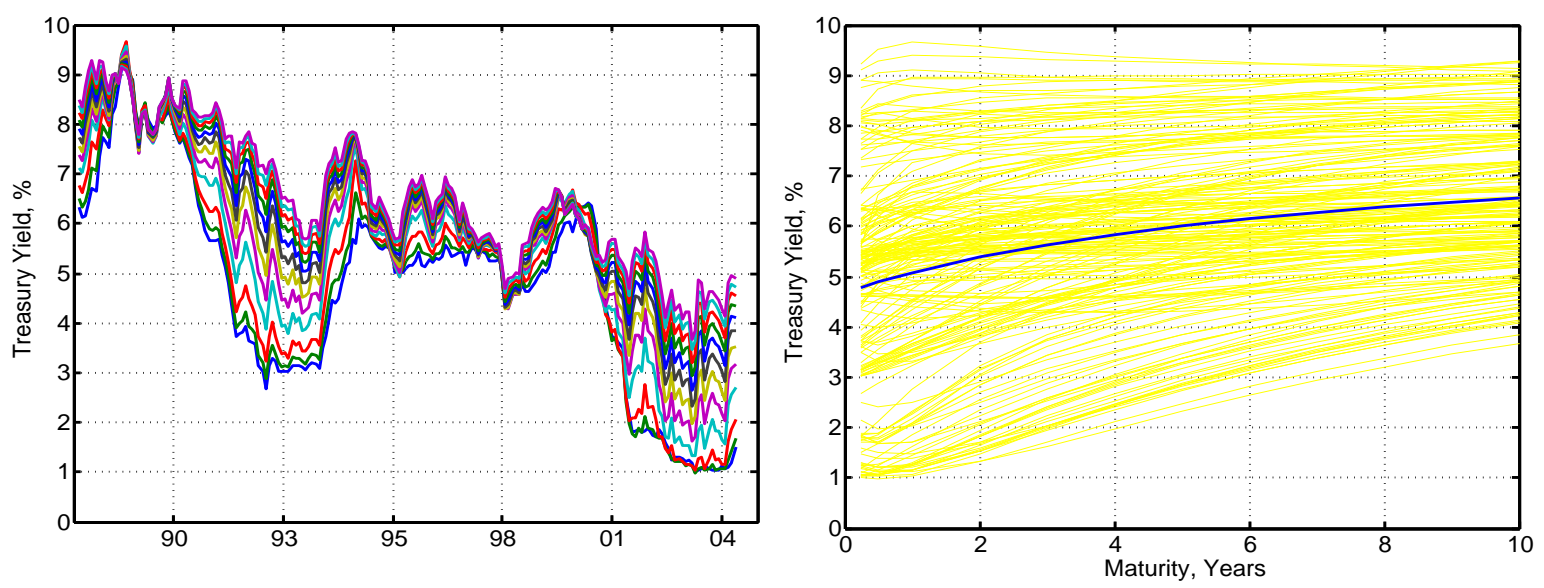

Figure 2. Time series and term structure of Treasury yields. Lines in the left panel plot the time series of Treasury yields at different maturities from three months to ten years. Lines in the right panel plot the term structure in each month, with the bold solid line denoting the mean term structure. Data are from the Federal Reserve Board. 

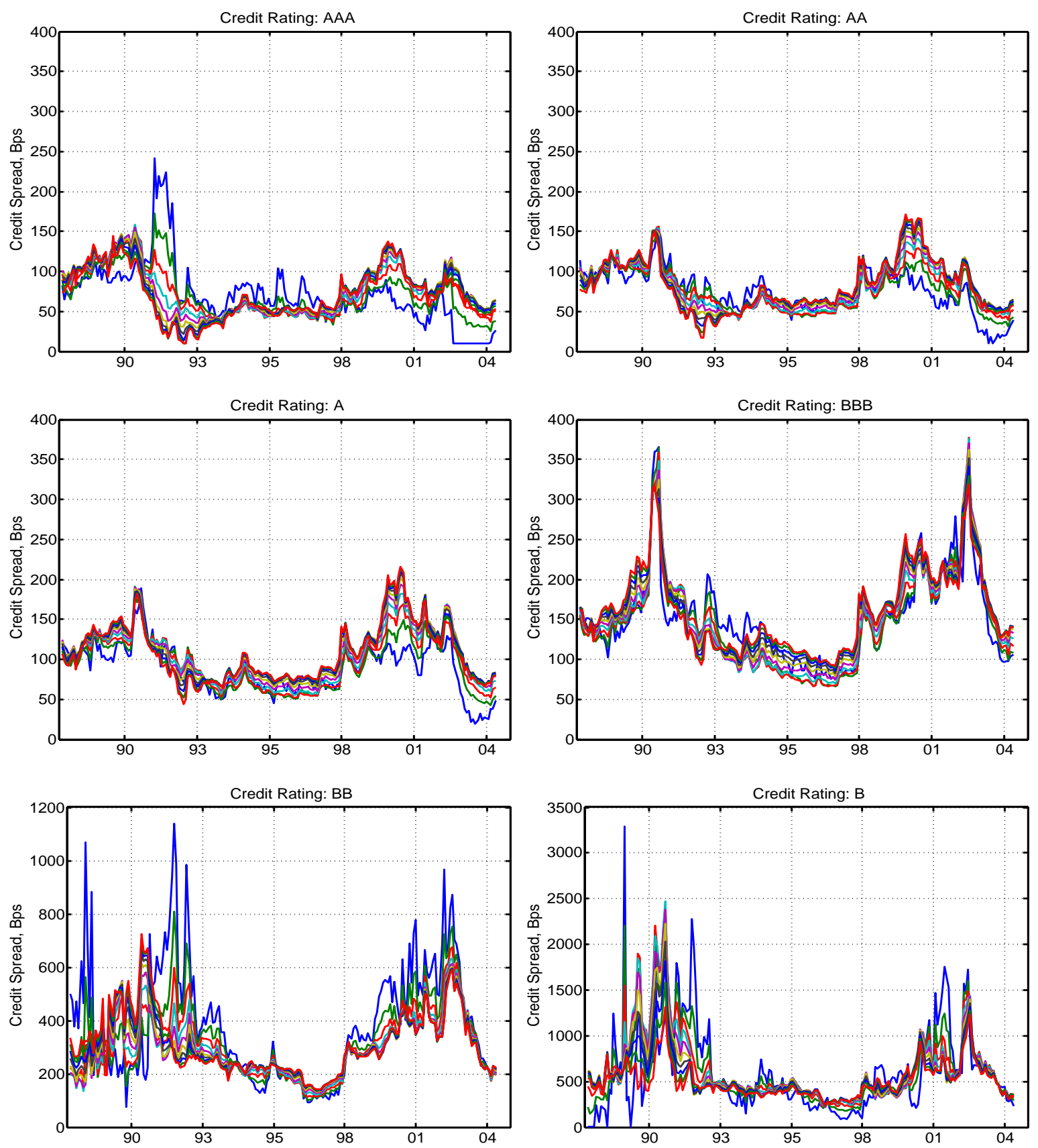

Figure 3. Time series of credit spreads on corporate bonds. Lines denote the time series of credit spreads. Each panel is for one credit rating group. The ten lines in each panel denote ten maturities from one to ten years. Data are monthly from January 1988 to June 2004, obtained from the Federal Reserve Board and Merrill Lynch. 

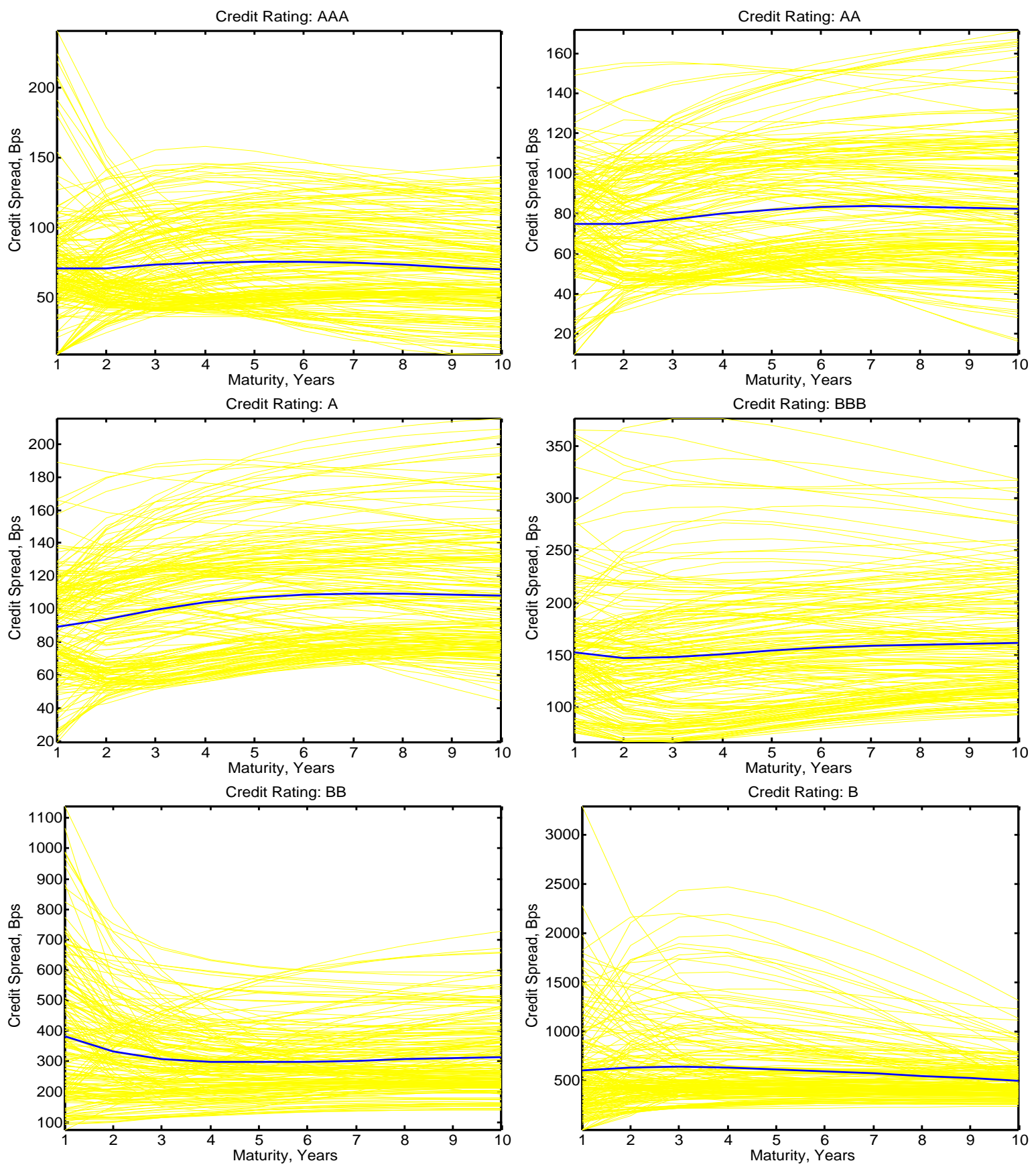

Figure 4. Term structure of credit spreads on corporate bonds. Lines denote the term structure of corporate credit spreads at different times. Each panel is for one credit rating group. Each line is for one month from January 1988 to June 2004, obtained from the Federal Reserve Board and Merrill Lynch. The bold line in each panel represents the mean term structure. 

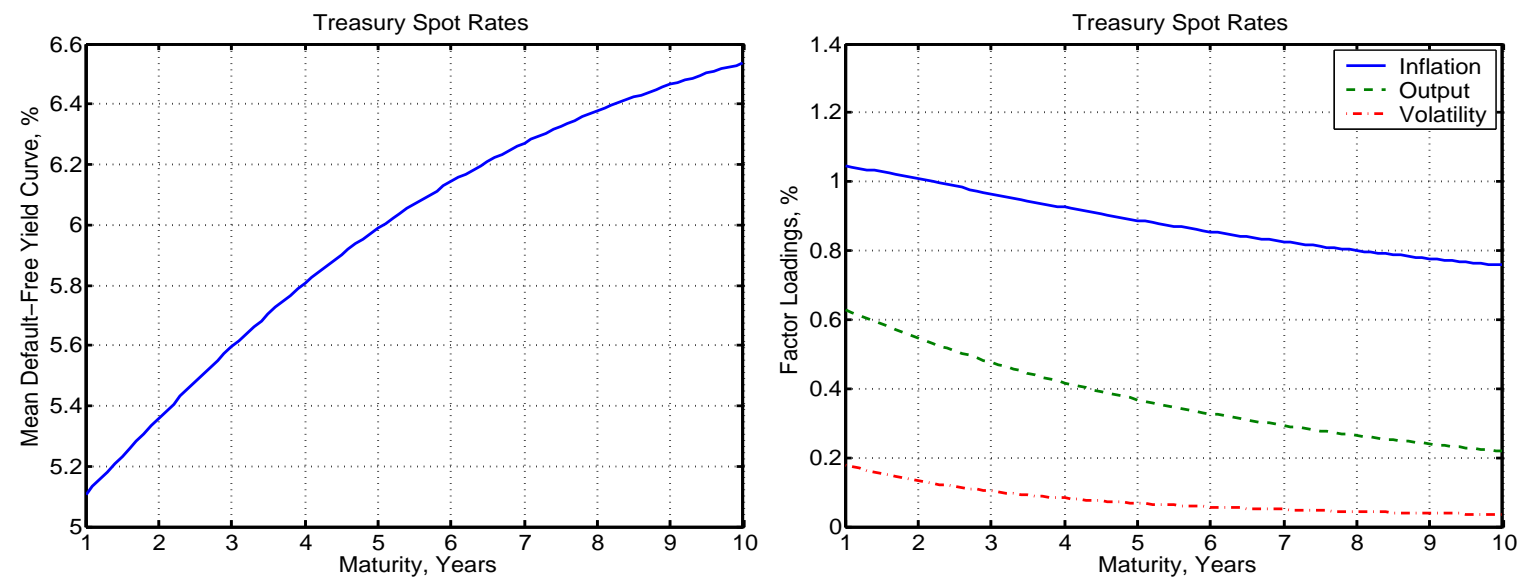

Figure 5. Mean treasury yield curve and factor loadings. The left panel plots $a(\tau) / \tau$, which determines the mean spot rate curve for the Treasury bond. Lines in the right panel plot the three elements of $b(\tau) / \tau$, which measure the contemporaneous response of Treasury spot rates to unit shocks on the three macroeconomic and financial factors. 

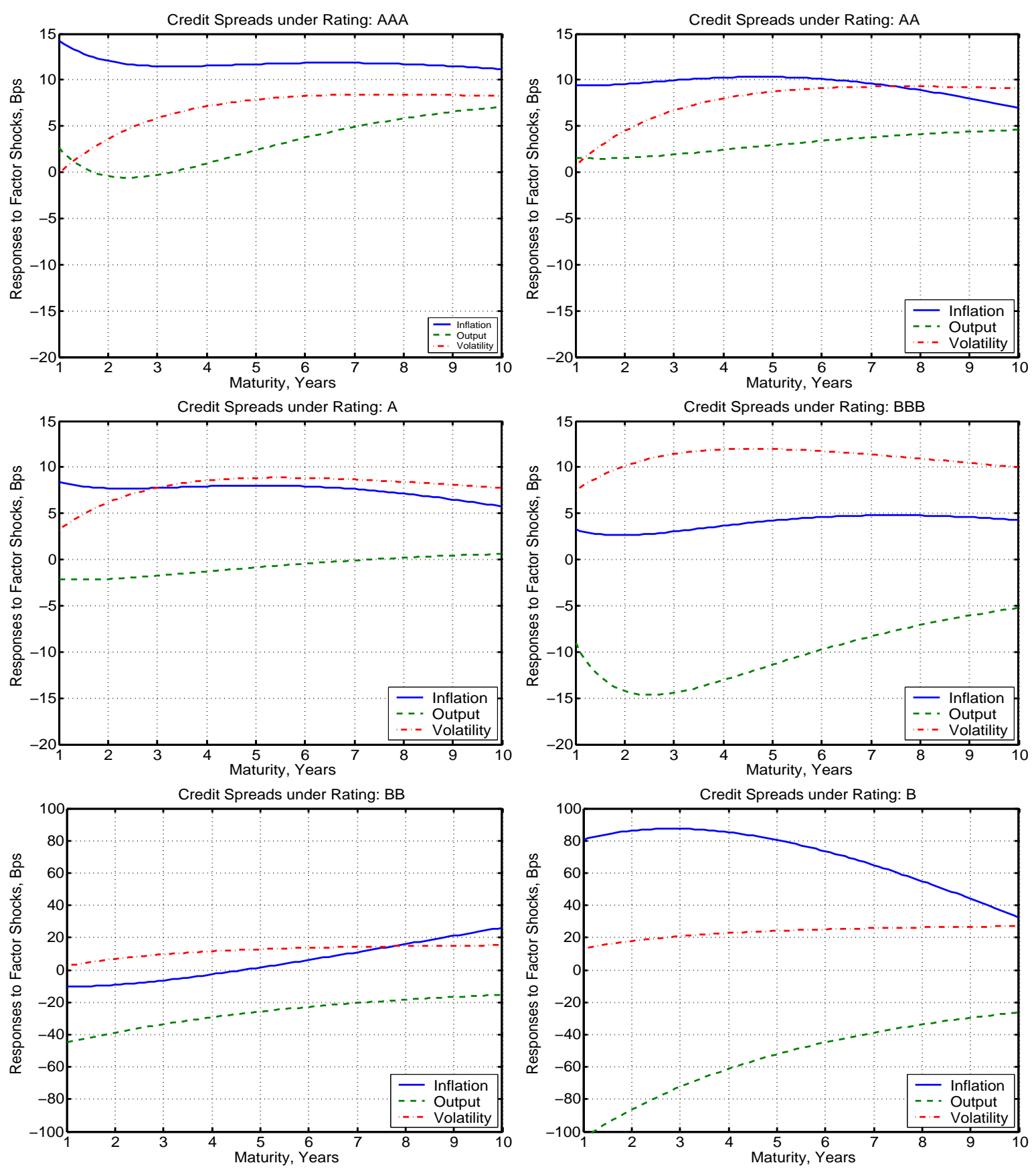

Figure 6. Contemporaneous response of the term structure of credit spreads to unit shocks on the dynamic economic factors. Lines denote the contemporaneous response of the term structure of credit spreads at different credit rating classes to unit shocks on the three economic factors. Each panel denotes one credit rating group. In each panel, the solid line denotes the impact of the inflation factor, the dashed line denotes the impact of the real output growth factor, and the dash-dotted line denotes the impact of the financial market volatility factor. 

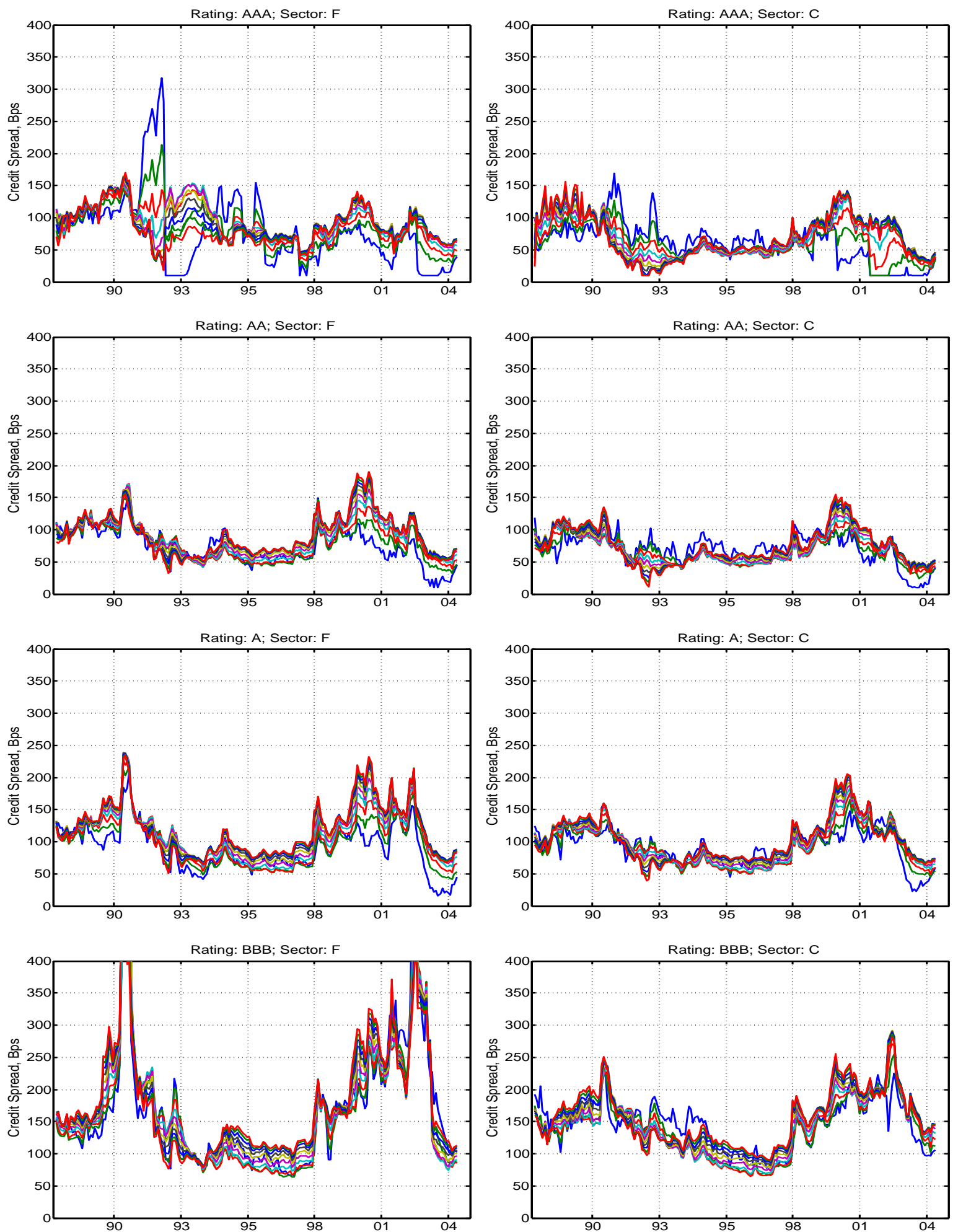

Figure 7. Time series of credit spreads across industry sectors and credit rating classes. Lines denote the time series of credit spreads. Each panel is for one credit rating class and industry sector. The ten lines in each panel denote ten maturities from one to ten years. Data are monthly from January 1988 to June 2004, obtained from the Federal Reserve Board and Merrill Lynch. 

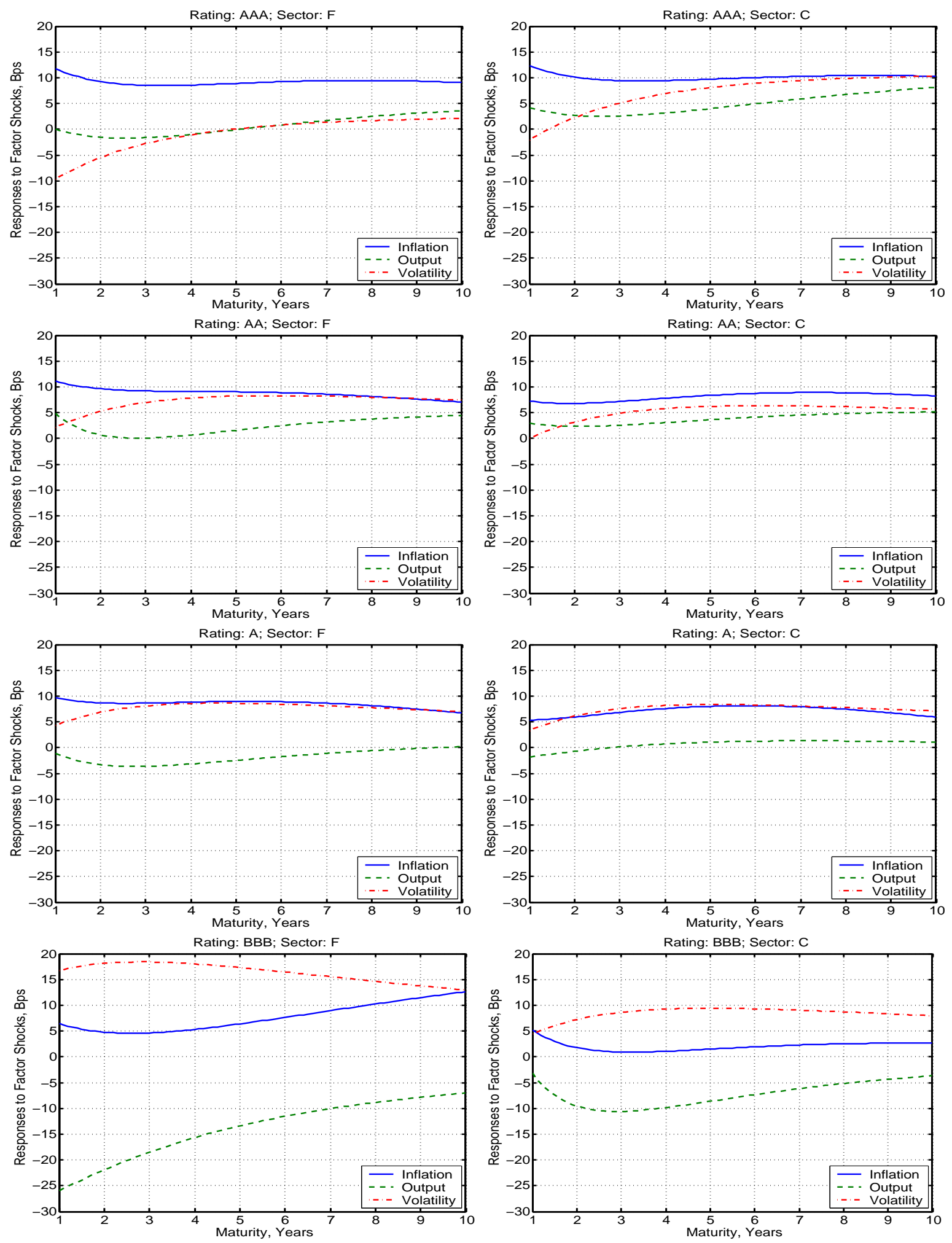

Figure 8. Contemporaneous response of the term structure of credit spreads to unit shocks on the economic factors. Lines denote the contemporaneous response of the term structure of credit spreads at different credit rating classes to unit shocks on the three macroeconomic and financial factors. Each panel denotes one credit rating group and industry sector. In each panel, the solid line denotes the impact of the inflation factor, the dashed line denotes the impact of the real output growth factor, and the dash-dotted line denotes the impact of the financial market volatility factor. 